\title{
- A potential link between waterfall recession rate and = bedrock channel concavity
}

\author{
Eitan Shelef, ${ }^{1,2}$ Itai Haviv, ${ }^{2}$ Liran Goren, ${ }^{2}$
}

Corresponding author: Eitan Shelef, Department of Geological \& Environmental Science, University of Pittsburgh, Pittsburgh, PA, 15260. (shelef@pitt.edu)

${ }^{1}$ Department of Geological \&

Environmental Science, University of

Pittsburgh, Pittsburgh, PA, USA.

${ }^{2}$ Department of Geological and

Environmental Sciences, Ben Gurion

University, Beer Sheva, Israel. 


\section{Abstract.}

${ }_{4}$ The incision of bedrock channels is typically modeled through the stream

5 power or the shear stress applied on the channel bed. However, this ap-

- proach is not valid for quasi-vertical knickpoints (hereafter waterfalls),

7 where water and sediments do not apply direct force on the vertical face

$s$ and waterfall retreat rate is often modeled as a power function of drainage

• area. These different incision modes are associated with two measurable

1o exponents: the channel concavity, $\theta$, that is measured from the channel to-

pography and is used to evaluate the exponents of drainage area and slope in the channel incision model, and $p$, that is measured from the location

of waterfalls within watersheds, and evaluates the dependency of the waterfall recession rate on drainage area. To better understand the relations between channel incision and waterfall recession we systematically compare between the exponents $p$ and $\theta$. These parameters were computed from digital elevation models (30 m SRTM) of 12 river basins with easily detectable waterfalls. We show that $p$ and $\theta$ are: (1) similar within uncertainty, (2) come from a similar distribution, and (3) covary for networks with a large number of waterfalls ( $\gtrsim 10)$. In the context of bedrock incision models this hints that the same processes govern waterfall retreat rate and the incision of non-vertical channel reaches in the analyzed basins, and/or that downstream incision can dictate waterfall retreat rate. 


\section{Introduction}

${ }_{24}$ Quantification of landscape response to climatic and tectonic changes is a key component ${ }_{25}$ in predicting topographic sensitivity to future changes, and in reconstructing past changes

26

27

28

29

$$
E=K A^{m} S^{n},
$$

34 where $K\left[\mathrm{~L}^{1-2 m} / \mathrm{T}\right]$ is termed the erodibility coefficient and depends on bedrock properties,

$$
\begin{aligned}
& C_{e}=K A^{m} S^{n-1} . \\
& \text { D R A F T }
\end{aligned}
$$

In this framework, an increased rate of base-level fall $(U[\mathrm{~L} / \mathrm{T}])$ is communicated to the upper reaches of the channel network through upstream recession of oversteepend channel segments, namely, knickpoints [e.g., Rosenbloom and Anderson, 1994; Whipple and Tucker, 1999; Bishop et al., 2005; Crosby and Whipple, 2006]. When the knickpoint is non-vertical, its recession rate (i.e., knickpoint celerity: $C_{e}[\mathrm{~L} / \mathrm{T}]$ ) can be derived from the channel incision model (equation (1)) [Rosenbloom and Anderson, 1994; Whipple and Tucker, 1999; Bishop et al., 2005; Haviv et al., 2006; Berlin and Anderson, 2007]: 
${ }_{43}$ The celerity, $C_{e}$, is independent of the slope $(S)$ in two commonly assumed scenarios:

${ }_{44}$ (1) when $n=1$ [Rosenbloom and Anderson, 1994; Berlin and Anderson, 2007], such

${ }_{45}$ that $m / n=m$, and (2) when the slope of the knickpoint is the slope predicted for a

${ }_{46}$ steady state landscape under the new rate $\left(U_{n}\right)$ of base level fall (i.e., $U_{n}=E$ such that

${ }_{47} S=\left(\frac{U_{n}}{K}\right)^{1 / n} A^{-m / n}$ can be substituted into equation (2)). In both cases equation (2)

48 results in

$C_{e} \propto A^{m / n}$

49 where in the latter case $C_{e}$ also depends on $U$ [e.g., Niemann et al., 2001; Wobus et al., so 2006b].

${ }_{51}$ When $U$ and $K$ are generally uniform along the channel, the ratio $m / n$ equals the

52

53

$$
C_{e} \propto A^{\theta}
$$

54 When a knickpoint is quasi vertical (i.e., a waterfall) such that water and sediment

channel concavity index, $\theta$, that is typically computed from linear relations between $\log (S)$ and $\log (A)$ or between topographic elevation. In that case, equation (3) becomes:

all without applying direct force on the knickpoint face, the assumptions that underly Equations 1 and 2 become invalid [Crosby and Whipple, 2006; Haviv et al., 2010]. In that case, waterfall recession is influenced by a variety of processes, including plungepool drilling, freeze-thaw and wet-dry cycles, and groundwater seepage. The intensity of these processes depends on factors such as cap-rock and sub-cap-rock strength and joint density, sediment concentration and grain-size distribution, water discharge, the microtopography of the waterfall lip, the waterfall height, temperature and rainfall fluctuations, water jet impact angle, and the properties of the lag-debris [e.g., Gilbert, 1907; Mason and 
63

64

65

66

67

68

69

$C_{e w}=B A^{p}$,

70

71

72

73

74

75

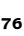

77

вз $p$ values span a wider range $(p=-3,0,0.24,0.33,0.54,1.125$; for Mackey et al. [2014];

s4 Weissel and Seidl [1998]; Haviv [2007]; DiBiase et al. [2015]; Berlin and Anderson [2007]; 
$\mathrm{X}-6$

SHELEF ET AL: WATERFALL RECESSION AND CHANNEL CONCAVITY

85

86

87

88

89

90

Crosby and Whipple [2006], respectively). These published data, however, are hindered by

the small number of reported $p$ measurements and the general lack of uncertainty bounds

for reported $p$ and $\theta$ values. Further, $p$ and $\theta$ values are often not measured over the same channel segments and, as far as we know, the covariance between them has not been explored.

In this study we compare $p$ and $\theta$ over the same channel sections while quantifying their uncertainty. We also explore the covariance between $p$ and $\theta$, and the influence of various factors on $p$. To do so we use existing and new methods to compute $p, \theta$, and their uncertainty from digital elevation models (DEMs) of 12 river basins with multiple waterfalls. Our analyses indicate that $p$ and $\theta$ are: (1) similar within uncertainty, (2) come from a similar distribution, and (3) generally covary. We also show that optimized $p$ values are sensitive to the variability in the basin area that drains to waterfalls, which could explain the wide range of $p$ values that has been reported in the literature.

\section{Method}

98

๑

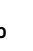

(1)

102

To explore the similarity between $p$ and $\theta$ we analyze 12 natural basins with multiple waterfalls in different climatic and lithologic conditions (Table 1, Table S1). We first detect the location of waterfalls and the uncertainty in their location in a systematic manner (Section 2.2). We then use these locations and uncertainties to compute the optimal $p$ and $\theta$ values (Sections 2.3, 2.4), and their uncertainty (Section 2.5) for each of the analyzed basins. For consistency, we compute the values of $\theta$ over the same channel sections used to compute $p$ (i.e., between the waterfalls and a downstream location that drains all waterfalls). To verify that our results are consistent across methods for $p$ and $\theta$ 
computation, we use three different methods to compute $\theta$ and two methods to compute $p$. The resulting $p$ and $\theta$ values are then compared.

\subsection{Study sites}

We explored the values of $p$ and $\theta$ by analyzing basins with multiple waterfalls identified using a 1 arc-second SRTM DEM ( $30 \mathrm{~m}$ for the studied basins) [Rodríguez et al., 2005] (Table 1, Table S1). The basins were selected based on the following criteria: (1) multiple waterfalls (to effectively constrain $p$ ); (2) waterfalls are clearly detectable over the DEM resolution (Section 2.2, Figures 1); (3) the drainage area at the waterfall $\left(A_{w}\right)$ in some of the selected basins spans a wide range of values such that in these cases it is unlikely that waterfall location can be explained solely via a drainage area threshold [i.e., Crosby and Whipple, 2006]; (4) basins span different precipitation regimes in order to explore the potential influence of precipitation on $p$ and $\theta$ [e.g., Zaprowski et al., 2005] (Table 1).

\subsection{Waterfall identification}

We applied a quasi-automatic waterfall identification procedure to detect waterfalls in a repeatable and efficient manner (Figure 2). We first used the DEM to visually detect all potential waterfalls within a basin and extract the profiles of channel segments that contain waterfalls. For each segment we identified the waterfall location and its boundaries using the following procedure: (a) for each node along the channel segment we recorded elevation and drainage area $\left(z_{i}, A_{i}\right.$, where $i$ is the node index); (b) the slope $\left(S_{i}\right)$ at each node was computed via a central difference scheme over a window of 9 nodes (a window size selected based on iterative experimentation) along the channel to suppress slope errors that propagate from elevation errors in the DEM [i.e., Wobus et al., 2006a]; (c) Values of 
$k_{s n}$ (normalized channel steepness index, [e.g., Wobus et al., 2006a]) were computed for

each channel node utilising $k_{s n_{i}}=S_{i} A_{i}^{0.5}$ (an exponent value of 0.5 is generally similar to that computed for most basins we studied, and is in agreement with values that are traditionally used) ; (d) waterfall location was detected by finding the node of highest $k_{s n_{i}}$ where the slope across the waterfall also exceeds a prescribed threshold $(0.2$, in agreement with the upper slope limit of step-pool and cascade reaches [Montgomery et al., 1995; Montgomery and Buffington, 1997] as well as lag-debris reaches beneath waterfalls [Haviv et al., 2010; Haviv, 2007]); (e) The top and bottom boundaries of the waterfall were defined by progressing from the waterfall up- and down- stream until the first node where $S_{i}$ is smaller than half of the prescribed knickpoint threshold (i.e., $<0.1$ ). If $S_{i}$ does not decrease below this value; the channel is relatively steep so the waterfall is defined as not being sufficiently distinguishable and is excluded from the analysis. These boundaries are used as measures of uncertainty in waterfall location. We executed this routine over all basins and visually confirmed the location of the selected waterfalls and their boundaries (Figure 3)

\subsection{Computation of $p$ value}

\subsubsection{Time based optimization of $p$}

To compute $p$ for each basin we used an optimization procedure that minimizes the scatter in recession duration (i.e., the time-span of recession) among the observed waterfalls [e.g., Brocard et al., 2016]. This procedure relies on a commonly used assumption [e.g., Weissel and Seidl, 1998; Crosby and Whipple, 2006; Berlin and Anderson, 2007; Brocard et al., 2016] that all waterfalls initiated as a single waterfall that was located at the trunk channel at some initial time $t_{s}$, and over the time period between $t_{s}$ and the 
present (hereafter recession duration) receded and bifurcated at tributary junctions to their current location. We also assume that the waterfall recession rate is described by equation (5) and that the value of $B$ and $p$ are uniform within the basin. These assumptions are similar to those used by other studies [Crosby and Whipple, 2006; Berlin and Anderson, 2007; Whittaker and Boulton, 2012; DiBiase et al., 2015; Brocard et al., 2016].

The $p$ value that optimizes the fit between modeled and natural waterfall locations can be computed either from the spatial misfit between the location of modeled and observed waterfalls [e.g., Crosby and Whipple, 2006; Berlin and Anderson, 2007], or from the temporal misfit in arrival time of the modeled waterfall to the location of the observed ones [e.g., Brocard et al., 2016]. We computed $p$ through the latter approach that is most consistent with the assumption that all waterfalls migrated to their current position over the same time period. The recession duration (i.e., the time-span of recession) between the initial waterfall location and the current one is cast as [following Crosby and Whipple, 2006; Berlin and Anderson, 2007]:

$t_{r}\left(N_{n}\right)=\sum_{i=1}^{N_{n}} \Delta t_{i}=\sum_{i=1}^{N_{n}} \frac{\Delta x}{C_{e w, i}} \delta_{i}$

where $N_{n}$ is the number of nodes between the initial waterfall location at $t_{s}$ and the current waterfall location, $\Delta t_{i}[\mathrm{~T}]$ is the recession duration between nodes $i$ and $i+1 . C_{e w, i}[\mathrm{~L} / \mathrm{T}]$ is the waterfall celerity between nodes $i$ and $i+1$ that is evaluated as $B A_{i}^{p}$ (equation (5)) where $A_{i}$ is the drainage area of the $i$ 'th node. $\Delta x$ is the the distance between DEM nodes in the cardinal directions, and $\delta_{i}$ is a dimensionless variable that equals 1 or $\sqrt{2}$ for cardinal and diagonal flow direction between nodes $i$ and $i+1$, respectively.

To compute $p$ in cases where the recession duration and initial waterfall location are unknown, we non-dimensionalized the duration of waterfall recession to: $t_{r}^{*}\left(N_{n}\right)=\sum_{i=1}^{N_{n}} \Delta t_{i}^{*}$, 
where $\Delta t_{i}^{*}=\Delta t_{i} / \Delta t_{0}$. We set $\Delta t_{0}=\frac{\Delta x}{B A_{0}^{p}}$ where $A_{0}$ is an arbitrary reference drainage area. The non-dimensional recession duration is:

$t_{r}\left(N_{n}\right)^{*}=\sum_{i=1}^{N_{n}} \Delta t_{i}^{*}=A_{0}^{p} \sum_{i=1}^{N_{n}} A_{i}^{-p} \delta_{i}$.

We find the optimal $p$ value while accounting for the uncertainty in waterfall positions. To do so, we computed the dimensionless recession duration ( $t_{r}^{*}$, equation (7)) between the initial waterfall location and each of the observed waterfalls for each $p$ value (from 0 to 2 in intervals of 0.01$)$. We then calculated the weighted misfit $\left(\chi_{r}^{2}\right)$ in recession duration between waterfalls:

$\chi_{r}^{2}=\frac{1}{N_{p}-1} \sum_{i=1}^{N_{p}} \frac{D_{i}^{2}}{\sigma_{i}^{2}}=\frac{1}{N_{p}-1} \sum_{i=1}^{N_{p}} \frac{t_{r, i}^{*}-\overline{t_{r}^{*}}}{\sigma_{i}^{2}}$,

where $N_{p}$ is the number of waterfalls, $D_{i}$ is the difference in $t_{r}^{*}$ between the $i$ th waterfall $\left(t_{r, i}^{*}\right)$ and the mean $t_{r}^{*}$ for all waterfalls $\left(\bar{t}_{r}^{*}\right)$, and $\sigma_{i}$ is a measure of uncertainty in recession duration computed from the standard deviation of the nondimensional recession time to the top and bottom boundaries of the $i$ th waterfall (because this is a standard deviation of two values only, it equals half of the difference in $t_{r}^{*}$ between these top and bottom boundaries). The best fit $p$ value is the one that produces the lowest $\chi_{r}^{2}$ value (Figure 4). The method successfully recovered the correct $p$ values from synthetic experiments where waterfall locations were modeled with a prescribed $p$ values.

As long as the initial location of the waterfall is at the trunk stream downstream of all waterfalls, the optimization of $p$ is insensitive to the exact initial location of the waterfall and the duration of waterfall recession. This is because waterfall recession along a trunk channel downstream of all waterfalls shifts $t_{r}^{*}\left(N_{n}\right)$ by a constant value for all waterfalls. Hence, the initial location of the waterfall can be prescribed at any arbitrary location in 
the trunk channel without affecting the optimization results that rely on minimizing the scatter in $t_{r}^{*}\left(N_{n}\right)$ between all waterfalls. This facilitates finding the best fit $p$ without knowing the recession duration and the exact initial location of the waterfall.

The method described above differs from the time-based optimization of Brocard et al. [2016] in that it is designed to compute $p$ while accounting for the uncertainty in waterfall location. To explore whether the $p$ values produced by the time-based approach we used is similar to that produced by the distance-based approach of Crosby and Whipple [2006] and Berlin and Anderson [2007], we also developed a distance-based optimization procedure that can recover $p$ when both the duration of recession and the exact initial location of the waterfalls are unknown. The $p$ values produced by these two approaches are equal within error (see SI).

\subsubsection{Optimization of $p$ with a critical area threshold}

To account for the possibility that waterfall recession is halted when the basin area that drains to the waterfall is below a critical threshold $\left(A_{c}\left[\mathrm{~L}^{2}\right]\right.$, Crosby and Whipple [2006]) we also computed the optimal $p$ for:

$C_{e w}=B\left(A-A_{c}\right)^{p}$.

Under these conditions $C_{e w}=0$ when $A_{c} \geq A$. The $A_{c}$ value for each basin was determined as the minimum drainage area over all the waterfalls in the basin. The optimal $p$ value is found by minimizing $\chi_{r}^{2}$ as explained in section 2.3 (equation (8)).

\subsection{Extraction of $\theta$ value}

We computed $\theta$, and the uncertainty associated with it, using slope-area $(S-A)$ [e.g., Hack, 1973; Whipple and Tucker, 1999; Wobus et al., 2006a], and $\chi-z$ [e.g., Royden et al., 
these assumptions hold, the integration of channel slope over the distance $l-l_{b}$ along the channel yields [Perron and Royden, 2012; Willett et al., 2014; Shelef and Hilley, 2014]:

$$
\begin{aligned}
z(l) & =z\left(l_{b}\right)+\int_{l_{b}}^{l} S(l) d l \\
& =z\left(l_{b}\right)+k_{s} \int_{l_{b}}^{l} A^{-\theta} d l \\
& =z\left(l_{b}\right)+k_{s} A_{0}^{-\theta} \chi(l) .
\end{aligned}
$$

where $z\left(l_{b}\right)$ is the $z$ value at $\chi=0$. equation (11) demonstrates that when $\chi$ is calculated with a $\theta$ value that is representative of the analyzed channel and under the above assumptions, the relation between $\chi(l)$ and $z(l)$ is linear and $k_{s} A_{0}^{-\theta}$ is the coefficient of proportionality. This equation also implies that when $\chi$ is computed for multiple tributaries, and is integrated in the up-flow direction from a common point downstream, the correct $\theta$ value should not only linearize all the profiles in $\chi-z$ space, but also collapse all tributaries to a single line [Perron and Royden, 2012].

If the channels downstream of waterfalls are assumed to be at steady state, an optimal $\theta$ can be identified through an iterative search for a value that minimizes the deviation from a least square linear regression between $\chi$ and $z$ [Perron and Royden, 2012; Royden and Perron, 2013; Mudd et al., 2014] downstream of waterfalls. We used a range of $\theta$ values (from 0 to 2 in intervals of 0.01 ) to compute $\chi$ for each DEM node along tributaries that extend from the prescribed initial waterfall location to the bottom of waterfalls. We integrated $\chi$ using the rectangle rule to better capture the discrete changes in $\chi$ across channel junction [Mudd et al., 2014]. For each $\theta$ value, we computed the least square linear regression between $\chi$ and $z$ and calculated the misfit between the data and the linear model using equation (8) where $D_{i}$ is the difference between the observed and 
$\mathrm{X}-14$

SHELEF ET AL: WATERFALL RECESSION AND CHANNEL CONCAVITY

251

predicted elevation at the $i$ 'th node, $\sigma_{i}$ is the DEM vertical error (i.e., $10 \mathrm{~m}$ ), and $N_{p}$ is the number of $\chi-z$ pairs. The optimal $\theta$ value minimizes the misfit (equation (8)).

Non-linear $\chi-z$ relations may occur when temporally and/or spatially varying uplift, climate, and rock properties affect the geometry of the channel network [e.g., Royden and Perron, 2013; Mudd et al., 2014; Goren et al., 2014]. To acknowledge this possibility we computed $\theta$ through a binning approach [after Goren et al., 2014] that minimizes the scatter of $z$ values within each $\chi$ bin with multiple tributaries, so that it does not force the same linear relation over the entire $\chi$ and $z$ range. For each $\theta$ value, the procedure divides the range of $\chi$ values to 100 bins (based on an iterative experiment that shows that stable $\theta$ values are attained with more than 20 bins), and computes equation (8) for bins that contain more than one tributary. The optimal $\theta$ value is that which minimizes equation (8), where $D_{i}$ is the standard deviation of $z$ values within each bin, and $\sigma_{i}$ is the DEM vertical error (i.e., $10 \mathrm{~m}$ ).

\subsection{Uncertainty in $p$ and $\theta$}

The values of $p$ and $\theta$ are often reported without a measure of uncertainty, thus inhibiting a comparison that accounts for the uncertainty in each of these parameters. For $\theta$ values computed from the slope of the least square linear regression of $\log (S)$ vs. $\log (A)$ (Section 2.4.1), the uncertainty in $\theta$ for each of the basins is reported as two standard deviations of the computed slope [Montgomery and Runger, 2010]. For $\theta$ values computed from $\chi-z$ relations (Section 2.4.2), as well as for $p$ values computed from $t_{r}^{*}$ (Section 2.3), we calculated the uncertainty for each basin through an iterative bootstrap approach that repeatedly computes $p$ (or $\theta$ ) for subsets of the flow pathways in each basin. This is executed for 50 iterations, where in each iteration we compute the optimal $p$ (or $\theta$ ) value 
273

for an arbitrarily chosen subset of the flow pathways (Figure 4). We then compute the lower and upper uncertainty bounds in $p$ (or $\theta$ ) for each basin from the 2.5 and 97.5 percentiles of the optimal $p$ (or $\theta$ ) values computed in these 50 iterations (Figure 4). In each iteration the number of flow pathways is the integer value closest to $75 \%$ of the total number of flow pathways.

\section{Results}

\subsection{Waterfalls, longitudinal profiles, and their characteristics}

Figure 3 shows river longitudinal profiles along the analyzed basins. We find that the elevation of the waterfalls in each basin is generally similar within uncertainty (i.e., the top and bottom boundaries of the waterfall, Figure 3). In some basins this elevation consistently changes with distance from the origin (e.g., Figure 3a-c,h), or is rather scattered (Figure 3f). Review of geologic maps (Table 1), air-photos, pictures (https://www.google.com/earth/, http://www.panoramio.com), and previous work [Melis et al., 1996; Ruiz, 2002; Weissel and Seidl, 1997, 1998; Berlin and Anderson, 2007] suggests that in most of the analyzed basins the waterfalls occur over an erosion-resistant sedimentary layer.

\subsection{Computed $p$ values}

Computed values of $p$ typically span a range of 0.3-0.9 (Figures 5, Table S1). High values of $p(\approx 1)$ occur in basins a and $\mathrm{k}$ and are associated with a low standard deviation $\left(\sigma_{a}\right)$, and relative standard deviation $\left(\sigma_{a} / \mu_{a}\right.$, where $\mu_{a}$ is the mean drainage area at waterfalls) of the drainage area at waterfalls (Figure 5a). The uncertainty in $p$ is sensitive to the number of waterfalls $\left(N_{p}\right)$ in the analyzed basin and suggests that this uncertainty stabi- 
$\mathrm{X}-16$

SHELEF ET AL: WATERFALL RECESSION AND CHANNEL CONCAVITY

292

lizes when $N_{p} \gtrsim 10$ (Figure $5 \mathrm{~b}$ ). Values of $p$ computed through the time-based method with and without a critical area threshold $\left(A_{c}\right)$ covary and are similar within uncertainty (Figure $5 \mathrm{c}$ ), where a model with $A_{c}>0$ typically produces lower $p$ values compared to a model with $A_{c}=0$. Values of $p$ do not display a clear covariance with precipitation, waterfall height, or slope (Figure 5d-f, height and slope are measured between the top and bottom waterfall boundaries). The $\chi_{r}^{2}$ optimization curves (SI) tend to be better constrained for basins with large number of waterfalls (Table S1). The $p$ value we computed for basins e-j $\left(0.49_{-0.05}^{+0.04}, 0.44_{-0.04}^{+0.28}, 0.39_{-0.03}^{+0.02}\right.$, respectively, computed with $\left.A_{c}=0\right)$ differs from the $p$ value estimated by Weissel and Seidl [1998] for the same catchment $(p \sim 0)$. This deviation likely reflects differences in the DEM resolution, number of waterfalls, and optimization technique. This study uses DEMs of $30 \mathrm{~m}$ resolution, 47 waterfalls, and the aforementioned $p$ optimization technique, whereas the study of Weissel and Seidl [1998] used DEMs of $500 \mathrm{~m}$ resolution, 11 waterfalls, and visual approximation of $p$. Further, this study analyzed each basin separately, whereas Weissel and Seidl [1998] analyzed basins e-g together, starting approximately $150 \mathrm{~km}$ downstream of the confluence where these basins join.. The $p$ values computed for basins $\mathrm{h}$ and $\mathrm{i},\left(0.51_{-0.1}^{+0.12}, 0.53_{-0.07}^{+0.06}\right.$, respectively, computed with $A_{c}=0$ ) are similar to the value computed by Berlin and Anderson [2007] for these two basins combined using a distance based-optimization $(p=0.54)$.

\subsection{Computed $\theta$ values}

Computed values of channel concavity $(\theta)$ typically span a range of 0.3-0.7 (Figure 6, Table S1). In contrast to $p$, the uncertainty in $\theta$ is generally independent on the number of waterfalls (Figure 6a), and $\theta$ is generally insensitive to $\sigma_{a}$ (Figure 6b). $\theta$ does not show a clear covariance with precipitation (Figure 6c). The $\theta$ values computed through slope- 
314

area relations somewhat deviate from those computed based on linear or binning based optimization of $\chi-z$ relations $\left(\theta_{\chi-z-l i n}\right.$ and $\theta_{\chi-z-b i n}$, respectively, Section 2.4, Figure 7).

In some basins the $\chi-z$ relations for the flow pathways downslope of the waterfalls are scattered and so are the slope area relations, suggesting that these basins deviate from the linear relation expected when channels are at steady state and lithology and uplift are spatially homogenous (SI).

\subsection{Comparison of $\theta$ and $p$}

Comparison of $p$ and $\theta$ shows that they are generally similar within uncertainty (Figure 7 , Tables $1, \mathrm{~S} 1$ ). The optimal $p$ and $\theta$ values generally covary for basins of $\gtrsim 10$ waterfalls, Figure 7c). Least square linear regression between $p$ computed with $A_{c}=0$ and $\theta$ computed through all the aforementioned methods produces $\theta=0.054( \pm 0.13)+0.95( \pm 0.31) p$ (uncertainty is reported based on $95 \%$ confidence interval), with an $R^{2}=0.64$, and a probability $(\mathrm{p})$ value of $2.4 \times 10^{-6}$. Similar analysis for $p$ computed with $A_{c}>0$ produces $\theta=0.006+1.19 p$ with an $R^{2}=0.59$ and a probability (p) value of $1.2 \times 10^{-5}$. Note that in both cases the intercept is $<0.1$ and the slope is close to unity, suggesting that $p$ and $\theta$ are generally similar. A ranked correlation produces a Kendall correlation coefficient of 0.55 and a probability (p) value of $4.4 \times 10^{-4}$. The difference between $p$ and $\theta$ is maximal when $p$ values are high (Figure 7a). A Kolmogorov-Smirnov test that compared the distributions of $p$ and $\theta$ for all basins failed to reject the null hypotheses that $p$ and $\theta$ are drawn from the same population. Similarly, a Wilcoxon signed rank test that compared the paired (by basin) values of $p$ and $\theta$ failed to reject the null hypothesis that the population of differences between $p$ and $\theta$ pairs comes from a distribution whose median is zero. Note that in both of these tests the null hypothesis (i.e., similarity of $p$ 
and $\theta)$ is not rejected despite the very conservative significance level used $(\alpha=0.5$, an order of magnitude larger than the commonly used $\alpha=0.05)$.

\section{Discussion}

\subsection{Similarity between $p$ and $\theta$}

The similarity between $p$ and $\theta$ is supported through multiple means of comparison. Whereas the similarity 'within uncertainty' (Figure 7a) may depend on how the uncertainty in $p$ and $\theta$ is computed, the statistical tests are more robust and suggest that the values of $p$ and $\theta$ are drawn from the same population (i.e., Kolmogorov-Smirnov test), and that when matched by a basin, neither $p$ or $\theta$ is consistently higher than the other (i.e., Wilcoxon signed rank test). The covariance between $p$ and $\theta$ (for basins with 10 waterfalls or more), and their alignment along a $\sim 1: 1$ line further supports their similarity.

One interpretation of the similarity between $p$ and $\theta$ is that it stems from the functional similarity between $t_{r}^{*}$ and $\chi$ (Equations 7,10 ), where both $t_{r}^{*}$ and $\chi$ at the waterfall can represent the duration of waterfall recession [e.g., Whipple and Tucker, 1999; Perron and Royden, 2012; Goren et al., 2014]. Conceptually, when all tributaries collapse to a single line in $\chi-z$ space, and the waterfalls are of equal elevation, an equality of $p$ and $\theta$ is inevitable (Figure 8a,b). However, perfect alignment of $\chi$ and $z$ rarely occurs in natural settings, so that different values of $p$ and $\theta$ may occur. For example, Figures $8 \mathrm{c}$ and $8 \mathrm{~d}$, show a scenario where waterfalls are of equal elevation but the $\theta$ value that minimizes the scatter in $z$ for all $\chi$ values along the channels (Figure 8c) differs from the $p$ value that minimizes the scatter in $t_{r}^{*}$ at the waterfalls only (Figure 8d). Similarly, Figures 8e, and 8f, show a scenario with a perfect alignment of $\chi$ and $z$ but waterfalls at different elevations, such that once again the $\theta$ value that minimizes the scatter in $z$ for all $\chi$ values 
(Figure 8e) differs from the $p$ value that minimizes the scatter in $t_{r}^{*}$ at the waterfalls only (Figure 8f). These differences between $p$ and $\theta$ occur because $p$ minimizes the scatter in $t_{r}^{*}\left(\right.$ or $\chi$ ) at the waterfall location only, while $\theta$ minimizes the scatter in $z$ for $\chi\left(\right.$ or $t_{r}^{*}$ ) values everywhere along the analyzed channels.

In most of the analyzed basins waterfalls are approximately at the same elevation (within uncertainty, Figure 3). Whereas this can be interpreted as if the similarity between $p$ and $\theta$ stems from the idealized case described in Figure 8b, the lack of clear relations between the spread in waterfall elevations and the difference between $p$ and $\theta(\mathrm{SI})$, as well as the scattered $\chi-z$ relation for the analyzed basins (SI) suggests that the setting described in Figure 8b is unlikely. Given that the optimization of $\theta$ assigns equal weighting to all points along the channel profile, and that of $p$ accounts for waterfall location only, the similarity between $p$ and $\theta$ may capture commonalities between the processes that shape the channel profile and those that determine the location of waterfalls.

\subsection{Potential process-based rationale for the similarity of $p$ and $\theta$}

In the context of the channel incision law, $p=\theta=m / n$ suggests that the exponent value that describes the influence of drainage area $(A)$ on waterfall celerity is similar to that which describes the influence of $A$ on the celerity of non-vertical waterfalls (Section 1). This functional similarity may have several explanations.

A potential explanation for $p=m / n$ is that waterfall celerity is primarily influenced by water discharge and channel width, for which $A^{m / n}$ is a proxy (i.e., $m / n=c(1-b)$ where $c$ and $b$ are exponent relating drainage area to channel discharge and width, respectively, Whipple and Tucker [1999]). For example, discharge can influence the retreat of a quasi vertical waterfall face through plunge pool erosion, by shear on sub-vertical slabs which 
will eventually topple, by removing and breaking boulders which can buttress the waterfall

face, by supplying sediments that can enhance erosion, and by influencing wet-dry related weathering of the waterfall face. Since water velocity matters in all these processes, the width of the channel at a given discharge also matters. Hence, waterfall recession may be a function of $A^{m / n}$. Whereas multiple factors influence waterfall celerity (see Section 1), many of these factors can covary with channel geometry and discharge, and therefore with $A^{m / n}$. Further exploration of the relations between these different factors and $A^{m / n}$ is needed to support this potential explanation, and to evaluate the relative influence of processes that do not depend on $A$ on waterfall recession.

An alternate explanation for the similarity between $p$ and $m / n$ is that the recession of a waterfall, and that of downstream non-vertical channel segments are dependent. Such dependency was suggested by Haviv et al. [2010], who explored the recession of a waterfall with a resistant cap-rock underlain by a weaker sub-cap-rock. In that case, Haviv et al. [2010] demonstrated that a recession of a non-vertical channel segment downslope of a waterfall (driven by downstream incision) can result in increased waterfall height once the receding segment abuts against the waterfall (as long as the vertical incision rate below the waterfall is greater than that upstream of the waterfall). When the waterfall height reaches a threshold for gravitationally induced failure, the waterfall fails and recedes, the resulting debris is transported down the channel, and the process repeats (Figure 9).

A mechanism in which the waterfall celerity is dependent on (i.e., enslaved to) the celerity of the downstream channel segment requires that over long time-scales the waterfall celerity $\left(C_{e w}\right)$ equals the celerity of non-vertical channel segments $\left(C_{e}\right)$. In the context of Equations 3-5 this requires that the waterfall celerity coefficient $(B)$ equals the chan- 
nel erodibility $K$. We are not aware of direct comparisons of these coefficients across basins with well defined waterfalls such as those explored in this study, however, the $B$ value computed by Berlin and Anderson [2007] for waterfalls in the Roan Plateau, CO $\left(B=1.37 \times 10^{-7}\left[\mathrm{~m}^{0.08} \mathrm{yr}\right]^{-1}\right.$, computed with $\left.p=0.54\right)$ is within the range of empirically calibrated $K$ values for models with $0.5 \leq m / n \leq 0.59$ and $n=1$ [Stock and Montgomery, 1999; Ferrier et al., 2013; Murphy et al., 2016]. However, a case where waterfall recession is faster than that imposed by channel incision downstream (i.e., $C_{e w}>C_{e}$ ) was shown by DiBiase et al. [2015] for the Big Tujunga Creek that is incised into the crystalline rocks of the San-Bernardino mountains, CA. The high recession rate of the Niagara falls [Gilbert, 1907], for example, is also unlikely to be in balance with the recession imposed by channel incision (i.e., Figure 9) downstream. These examples suggest that the factors that govern waterfall recession may vary in time and space, and that a single mechanism is unlikely to explain the variety of observed phenomena. Direct comparison of $K, B, p$, and $\theta$ in locations where erosion rate, as well as the duration and spatial extent of waterfalls retreat are well constrained, can reveal whether, and under what conditions, waterfall recession is enslaved to that of downstream channel segments (Figure 9).

\subsection{Examination of assumptions}

18 The assumption that all waterfalls initiated as a single waterfall at the trunk channel downstream of all waterfalls underlies our computation of $p$. Whereas we could not test for this assumption, such assumption was previously made for some of the analyzed basins [i.e., Berlin and Anderson, 2007; Weissel and Seidl, 1998], and is common in studies of waterfall and knickpoint propagation [e.g., Crosby and Whipple, 2006; Brocard et al., 2016; DiBiase et al., 2015]. The occurrence of waterfalls over a sub-horizontal, erosion- 
$\mathrm{X}-22$

SHELEF ET AL: WATERFALL RECESSION AND CHANNEL CONCAVITY

424

425

426

427

428

resistant layer that is underlain by a weaker layer supports this assumption. This is because it suggests that this layer is initially incised at a downstream location where it is first transected by the stream, and the resulting waterfall then propagates upstream.

A second assumption, that underlies our computation of $p$, is that the celerity coefficient, $B$, and the exponent $p$, are spatially constant along the analyzed channel sections. Spatial homogeneity can stem from the spatial continuity of lithologic layers in many of the analyzed basins. This is suggested by geologic maps (Table 1), air-photos, pictures (https://www.google.com/earth/, http://www.panoramio.com), and published work [Melis et al., 1996; Ruiz, 2002; Berlin and Anderson, 2007] that indicate that in most of the analyzed basins the channel system is incised into sub-horizontal lithologic layers, and waterfalls occur over spatially continuous erosion-resistant layers underlain by weaker layers (except for basins e-g where this varies spatially [Weissel and Seidl, 1998] and at least some of the waterfalls are composed of a series of small waterfalls). The horizontal continuity of these layers can facilitate spatial homogeneity in $B$ and $p$, where waterfalls, as well as non-vertical channel segments downstream, everywhere recede over the same lithologic units [e.g., Haviv et al., 2006; Berlin and Anderson, 2007; Haviv, 2007; Haviv et al., 2010] (Figure 9). Observations concerning the stratigraphic position of waterfalls and whether their lower boundary is tied to a specific lithologic horizon can assist in evaluating the feasibility of stratigraphically controlled homogeneity.

The possibility that the similarity of $p$ and $\theta$ stems from enslavement of the waterfall celerity to that of the non-vertical channel downstream of the waterfall is underlain by few assumptions. First, this mechanism was suggested and explored for waterfalls over a resistant cap-rock underlaid by a weaker sub-cup-rock [Haviv et al., 2010] (this also 
447

448

449

appears to be the case in most of the basins we analyzed), and may not be valid for waterfalls in different settings. Second, in the context of Equations 3-5 and $p=\theta$ this mechanism requires that downstream channel recession is proportional to $A^{m / n}$, either because $n=1$ or because at the downstream channel segment denudation and uplift rates are approximately balanced (i.e., Section 1). Such a balance in the downstream channel segment is possible, despite the irregular channel profiles (Figure 3), because of the aforementioned lateral continuity of lithologic layers. In that case, where the spatial homogeneity of $\theta$ relies on the lateral continuity of specific layers but the value of $\theta$ is computed over the heterogeneous lithology of the entire channel system, it is assumed that this $\theta$ value is representative of the value of $\theta$ just downstream of the waterfall. In the context of the enslavement mechanism, if the latter assumptions hold so that denudation and uplift are balanced, the similarity between $p$ and $\theta$ is not necessarily indicative of $n=1$.

Finally, the comparison between $p$ and $\theta$ and its interpretation from a process perspective assumes that the underlying equations (i.e., Equations 2, 5) adequately describe the recession process. Whereas both equations were explored numerically and calibrated to field data [e.g., Rosenbloom and Anderson, 1994; Bishop et al., 2005; Crosby and Whipple, 2006; Whittaker and Boulton, 2012; Brocard et al., 2016], alternate or more complicated models can perform equally well or better [e.g., Crosby and Whipple, 2006; Lague, 2014]. A wide spread of $p$ values, or a clear indication that an important process is overlooked by equation (5) can raise doubts concerning the validity of this equation. Our results, pointing at a general consistency in the value of $p$ between basins, as well as at a similarity between $p$ and $\theta$, suggest that Equations 2 and 5 do capture aspects of the recession pro- 
cess that are consistent across the analyzed basins. This consistency lends some further support to the validity of these equations.

\subsection{The sensitivity of $p$ to basin properties and DEM resolution}

The uncertainty in $p$ is sensitive to the number of waterfalls $\left(N_{p}\right)$ within a basin (Figure 5b). In the context of our methodology for computing $p$, this suggests that when the number of waterfalls is small $\left(N_{p} \lesssim 10\right.$, Figure $\left.5 \mathrm{~b}\right)$, the influence of each of the flow pathways selected in a bootstrap iteration is large, such that a variety of optimal $p$ values can be produced depending on the selected subset. Our analyses therefore suggest that studies that aim to extract reliable $p$ values with the methodology we used should focus on basins with a large number of waterfalls $\left(N_{p} \gtrsim 10\right.$, Figure $\left.5 \mathrm{~b}\right)$.

The association between the exceptionally high $p$ value $(p \sim 1)$ of basins a and $\mathrm{k}$ $\left(0.94_{-0.12}^{+0.21}, 0.88_{-0.34}^{+0.24}\right.$, respectively, for a model with $\left.A_{c}=0\right)$, and the low variability in waterfalls drainage area $\left(A_{w}\right)$ that characterize these basins $\left(\sigma_{a} \sim 10^{6} \mathrm{~m}^{2}, \sigma_{a} / \mu_{a}<0.5\right.$, Figure 5a), points at a potential dependency between these parameters. Note that basin $\mathrm{d}$ is associated with a low $p$ despite a low standard deviation in $A_{w}\left(\sigma_{a}\right)$, yet this basin is associated with the lowest mean $A_{w}\left(\mu_{a}\right)$ of all basins $\left(\sim 2 \times 10^{6} \mathrm{~m}^{2}\right.$, Table S1), such that its relative standard deviation (i.e., $\sigma_{a} / \mu_{a}$ ) is higher than that of basins a and k. A dependency between $p$ and the variability in $A_{w}$ is aligned with the findings of Crosby and Whipple [2006], who computed high $p$ value $(p=1.125)$ for a basin with low variability in $A_{w}$.

Occurrence of high $p$ values is predicted for equation (5) when waterfalls drain a similar drainage area (i.e., low variability in $A_{w}$, Figures 1,5 a) but have different distributions of drainage area $(A)$ along the down-stream flow pathway. These high $p$ values occur because 
waterfalls that drain similar drainage areas (i.e., small $\sigma_{a}$ ) likely have similar $A$ values along the channel just downstream of the waterfall, while further downstream along the waterfall migration pathway (and yet upstream of where flow pathways merge next to the initial waterfall location) values of $A$ differ due to variations in the network topology. In that case, a high $p$ is preferred by the optimization procedure because it increases the similarity in recession duration $\left(t_{r}^{*}\right)$ by heavily weighting the low $A$ portion of the channel just downstream of the waterfall where the values of $A$ are similar among channels (i.e., equation (7)). As $\sigma_{a}$ increases, lower $p$ values are favored because they preferably weight the identical high $A$ portion of channels downstream of large confluences where channels merge. This topologic argument suggests that high $p$ values will be associated with low values of $\sigma_{a}$.

To explore this prediction, we run multiple $p$-optimization experiments where we used the topology (i.e., drainage area as a function of distance along the channels) for basin $g$, and imposed randomly positioned waterfalls within this basin topology. An initial set of $N_{s 1}$ waterfall locations, constrained by a prescribed range of drainage area, was randomly selected from all possible locations for basin g. From this initial set we excluded all waterfall locations that have other waterfalls draining to them. From this screened subset of random locations we then randomly selected a prescribed number of waterfalls $\left(N_{s 2}\right)$ and used it to optimize $p$. To test the sensitivity of $p$ to $\sigma_{a}$ in this synthetic situation, the dependent variable was $\sigma_{a}$, namely, the permissible range of drainage areas from which the $N_{s 1}$ locations are selected while maintaining the mean value of $A_{w}\left(\mu_{a}\right)$ approximately the same. We conducted 500 experiments with arbitrarily located waterfalls $\left(N_{s 1}=20, N_{s 2}=\right.$ 11). In each experiment we recorded the standard deviation of $A_{w}\left(\sigma_{a}\right)$, as well as the 
515

\section{Summary}

535 536

relative standard deviation $\left(\sigma_{a} / \mu_{a}\right)$ and optimal $p$ value. The results of this experiment show that a high value of $p$ is indeed associated with low $\sigma_{a}$. As $\sigma_{a}$ increases, the value of $p$ first declines steeply and then more gradually reaching approximately $p=0.5$ at higher $\sigma_{a}$ values (Figure 10).

The interpretation of $p$ values computed for low $\sigma_{a}$ should also account for the potential influence of DEM resolution. For example, waterfalls within the same basin may retreat according to equation (5) with a $p$ value of 0.5 up to the upper reaches of the basin, where the area that drains to waterfalls $\left(A_{w}\right)$ decreases and so does the waterfall celerity. When mapped over a low resolution DEM, all waterfalls may appear to have the same $A_{w}$ so the optimization procedure will prefer a higher value of $p$. In contrast, when mapped over high resolution DEM, small differences in $A_{w}$ will become apparent so $p=0.5$ can be recovered. Hence, DEMs of higher resolution will allow more accurate recovery of $p$, and for a given resolution, $p$ values computed for basins with high $\sigma_{a}$ are likely more reliable. For high values of $\sigma_{a}$ the optimal $p$ value for the synthetic experiments with arbitrary waterfall locations is in the range that is typical of $\theta$ (Figure 10). This can be interpreted as if the similarity between $p$ and $\theta$ is insensitive to the exact location of waterfalls, and that $p$ can be predicted from $\sigma_{a}$ (SI). However, the covariance between $p$ and $\theta$ for basins of $\geq 10$ waterfalls (Figure $7 \mathrm{c}$ ), together with the low covariance between $\theta$ and $\sigma_{a}$ (Figure 6c) suggests that the natural location of waterfalls is associated with significant subtleties in the value of $p$ that reflect differences in the underlying process.

35 This study explores the similarity between channel profile concavity (i.e., the exponent $\theta$ ) downstream of waterfalls, and the exponent $p$ that is used to model waterfall recession. 
537

We analyzed channel profiles and the locations of waterfalls at 12 basins with different climatic and lithologic conditions, and also developed a new method to compute the optimal value of $p$ and its uncertainty. Our results demonstrate that the values of $p$ and $\theta$ are similar within uncertainty, come from a similar population, and generally covary for basins with $\gtrsim 10$ waterfalls. In the context of the channel incision models this suggests that in the basins we analyzed waterfall recession is influenced by channel discharge and width as approximated by $A^{m / n}$, and/or that the waterfall celerity is enslaved to that of downstream channel segments.

Deviations between $p$ and $\theta$ primarily arise when $p$ values are relatively high due to low variability in the area that drains to waterfalls, or to high uncertainty in $p$. This may occur when waterfall recession decreases at low $A$ values and the DEM resolution is relatively low, or when the number of of waterfalls in a basin is $<10$. To avoid these influences, we recommend that $\mathrm{p}$ values be computed over basins with a relatively large spread in $A_{w}$ (i.e $\left.\sigma_{a} / \mu_{a}>1\right)$ and large number of waterfalls $(>10)$.

Future studies focused on the relations between the waterfall celerity coefficient $(B)$ and the channel erodibility coefficient $(K)$ may reveal whether, and for what conditions, waterfall celerity is similar to that of non-vertical channel segments. Such similarity would suggest that waterfall recession is enslaved to that of downstream segments. Furthermore, similarity would mean that landscape evolution models that implement the stream power or shear stress incision models are also suitable for simulating landscape evolution in the presence of waterfalls.

\section{Notation}

$A$ drainage area $\left[\mathrm{L}^{2}\right]$ 
$\mathrm{X}-28$ SHELEF ET AL: WATERFALL RECESSION AND CHANNEL CONCAVITY

${ }_{560} \quad A_{0}$ reference drainage area $\left[\mathrm{L}^{2}\right]$

${ }_{561} A_{c}$ critical drainage area threshold $\left[\mathrm{L}^{2}\right]$

${ }_{562} A_{i}$ drainage area at a node $i\left[\mathrm{~L}^{2}\right]$

${ }_{563} A_{w}$ area that drains to a waterfall $\left[\mathrm{L}^{2}\right]$

${ }_{564} A_{r}$ normalized drainage area used for plotting []

${ }_{565} B$ waterfall celerity coefficient $\left[\mathrm{L}^{1-2 p} / \mathrm{T}\right]$

${ }_{566} \quad b$ exponent that relates drainage area to channel width []

${ }_{567} C_{e}$ knickpoint celerity $[\mathrm{L} / \mathrm{T}]$

${ }_{568} C_{e} w$ waterfall celerity $[\mathrm{L} / \mathrm{T}]$

${ }_{569} C_{e w, i}$ the waterfall celerity between nodes $i$ and $i+1[\mathrm{~L} / \mathrm{T}]$

570 $c$ exponent that relates drainage area to channel discharge []

${ }_{571} D_{i}$ measure of difference used in computing $\chi_{r}^{2}$, units vary with model

${ }_{572} E$ erosion rate $[\mathrm{L} / \mathrm{T}]$

${ }_{573} i$ index of nodes []

${ }_{574} K$ erodibility coefficient in channel incision law $\left[\mathrm{L}^{1-2 m} / \mathrm{T}\right]$

${ }_{575} \quad k_{s}$ channel steepness $\left[\mathrm{L}^{2 m / n}\right]$

${ }_{576} \quad k_{s n}$ normalized channel steepness $\left[\mathrm{L}^{2 m / n}\right]$

${ }_{577} \quad k_{s n_{i}}$ normalized channel steepness at a node $i\left[\mathrm{~L}^{2 m / n}\right]$

${ }_{578} l$ along stream flow distance up flow from $l_{b}[\mathrm{~L}]$

${ }_{579} l_{b}$ along stream flow distance up flow from an arbitrary location [L]

sвo $m$ drainage area exponent in channel incision model []

${ }_{581} N_{n}$ number of nodes between the initial waterfall location at $t_{s}$ and some upstream node ${ }_{582}^{[-]}$ 
583

584

585

586

587

588

s89 $\quad S$ channel slope []

${ }_{590} \quad S_{i}$ slope at a node $i[]$

591

$597 \quad z$ elevation $[\mathrm{L}]$

${ }_{598} z_{i}$ elevation at a node $i[\mathrm{~L}]$

599

600

601

602

603

604

605

do not drain to each other []

$U$ uplift rate $[\mathrm{L} / \mathrm{T}]$

$\alpha$ statistical significance level []

$\delta t$ small time increment [T]

$N_{p}$ number of data points used in computing $\chi_{r}^{2}[]$

$N_{s 1}$ number of potential waterfall locations in a random selection process []

$N_{s 2}$ number of waterfalls selected from a subset of randomly positioned waterfalls that

$n$ slope exponent in channel incision model []

$t_{r}$ duration of waterfall recession [T]

$t_{r}^{*}$ non dimensional duration of waterfall recession []

$\overline{t_{r}^{*}}$ mean non dimensional duration of waterfall recession for all waterfalls in a basin[]

$t_{s}$ time of initial waterfall formation [T]

$U_{n}$ new uplift rate that is higher than the initial one $[\mathrm{L} / \mathrm{T}]$

$\delta_{i}$ dimensionless variable that equals 1 or $\sqrt{2}$ for cardinal and diagonal flow direction

between nodes $i$ and $i+1$, respectively []

$\Delta t_{0}$ reference waterfall recession duration $[\mathrm{T}]$

$\Delta t_{i}$ recession duration between nodes $i$ and $i+1[\mathrm{~T}]$

$\Delta t_{i}^{*}$ non dimensional waterfall recession duration [] 
$\mathrm{X}-30$ SHELEF ET AL: WATERFALL RECESSION AND CHANNEL CONCAVITY

606

607

608

609

610

611

612

613

614

615

616

617

618

619

620

621

622

623

624

625

$\Delta x$ distance between DEM nodes in the cardinal directions [L]

$\mu_{a}$ mean of $A_{w}$ in a basin $\left[\mathrm{L}^{2}\right]$

$\mu_{z}$ mean of waterfall elevation in a basin [L]

$\theta$ the ratio between the exponents $m$ and $n$ in the channel incision model []

$\theta_{S A}$ the value of $\theta$ computed from the $\log (A)$ vs. $\log (S)[]$

$\theta_{\chi-z}$ the value of $\theta$ computed from $\chi-z$ relations []

$\theta_{\chi-z-\operatorname{lin}}$ the value of $\theta$ computed from linear $\chi-z$ relations []

$\theta_{\chi-z-b i n}$ the value of $\theta$ computed from binned $\chi-z$ relations []

$\sigma_{i}$ measure of uncertainty used in computing $\chi_{r}^{2}$, units vary with model

$\sigma_{a}$ standard deviation of $A_{w}$ in a basin [ $\left.\mathrm{L}^{2}\right]$

$\sigma_{z}$ standard deviation of waterfall elevation in a basin [L]

$\Sigma_{z}$ vertical uncertainty in DEM [L]

$\chi$ transformation variable that links channel drainage area and length to elevation $[\mathrm{L}]$

$\chi_{r}^{2}$ measure of weighted misfit in recession duration []

Acknowledgments.

Data supporting our analysis is contained as tables and figures within the manuscript and

supplements. We thank Joel Johnson, and two anonymous reviewers for constructive and insightful comments that helped improve this manuscript. We are particularly thankful to Joel Scheingross for insightful and thorough review. E.S. thanks S. Willett and S. Gallen for constructive discussions regarding the impact of waterfalls on landscape evolution. 


\section{References}

Bagnold, R. (1966), An approach to the sediment transport problem from general physics, U.S. Geological Survey Professional Paper 422-1.

Berlin, M. M., and R. S. Anderson (2007), Modeling of knickpoint retreat on the Roan Plateau, western Colorado, Journal of Geophysical Research: Earth Surface, 112(F3), doi:10.1029/2006JF000553.

Bishop, P., T. B. Hoey, J. D. Jansen, and I. L. Artza (2005), Knickpoint recession rate and catchment area: the case of uplifted rivers in Eastern Scotland, Earth Surface Processes and Landforms, 30(6), 767-778, doi:10.1002/esp.1191.

Brocard, G. Y., J. K. Willenbring, T. E. Miller, and F. N. Scatena (2016), Relict landscape resistance to dissection by upstream migrating knickpoints, Journal of Geophysical Research: Earth Surface, 121(6), 1182-1203, doi:10.1002/2015JF003678.

Crosby, B. T., and K. X. Whipple (2006), Knickpoint initiation and distribution within fluvial networks: 236 waterfalls in the Waipaoa River, North Island, New Zealand, Geomorphology, 82(1), 16-38, doi:10.1016/j.geomorph.2005.08.023.

DiBiase, R. A., K. X. Whipple, M. P. Lamb, and A. M. Heimsath (2015), The role of waterfalls and knickzones in controlling the style and pace of landscape adjustment in the western San Gabriel Mountains, California, Geological Society of America Bulletin, 127(3-4), 539-559, doi:10.1130/B31113.1.

Dietrich, W. E., D. G. Bellugi, L. S. Sklar, J. D. Stock, A. M. Heimsath, and J. J. Roering (2003), Geomorphic transport laws for predicting landscape form and dynamics, in Prediction in Geomorphology, Geophysical Monograph Series, vol. 135, edited by P. Wilcock and R. Iverson, pp. 103-132, AGU, Washington, D. C., doi:10.1029/135GM09. 
648

649

650

651

652

653

654

655

Ferrier, K. L., K. L. Huppert, and J. T. Perron (2013), Climatic control of bedrock river incision, Nature, 496(7444), 206-209, doi:10.1038/nature11982.

Gasparini, N. M., R. L. Bras, and K. X. Whipple (2006), Numerical modeling of nonsteady-state river profile evolution using a sediment-flux-dependent incision model, $S D$ Willett et al., Geological Society of America Special Papers, 398, 127-141, doi:10.1130/ $2006.2398(04)$.

Gilbert, G. K. (1907), Rate of recession of niagara falls, U.S. Geological Survey Bulletin, $306,1-31$.

Goren, L. (2016), A theoretical model for fluvial channel response time during timedependent climatic and tectonic forcing and its inverse applications, Geophysical Research Letters, 43(20), 10-753, doi:10.1002/2016GL070451.

Goren, L., M. Fox, and S. D. Willett (2014), Tectonics from fluvial topography using formal linear inversion: Theory and applications to the Inyo Mountains, California, Journal of Geophysical Research: Earth Surface, 119(8), 1651-1681, doi:10.1002/2014JF003079.

Hack, J. T. (1973), Stream-profile analysis and stream-gradient index, Journal of Research of the US Geological Survey, 1(4), 421-429.

Hail Jr, W. J. (1992), Geology of the central Roan Plateau area, northwestern Colorado, U.S. Geological Survey Bulletin, 1787-R, 26p.

Haviv, I. (2007), Mechanics, morphology and evolution of vertical knickpoints (waterfalls) along the bedrock channels of the Dead Sea western tectonic escarpment., Ph.D. thesis, Hebrew University of Jerusalem, Israel.

Haviv, I., Y. Enzel, K. Whipple, E. Zilberman, J. Stone, A. Matmon, and L. Fifield (2006), Amplified erosion above waterfalls and oversteepened bedrock reaches, Journal 
671

of Geophysical Research: Earth Surface, 111(F4), doi:10.1029/2006JF000461.

Haviv, I., Y. Enzel, K. Whipple, E. Zilberman, A. Matmon, J. Stone, and K. Fifield (2010), Evolution of vertical knickpoints (waterfalls) with resistant caprock: Insights from numerical modeling, Journal of Geophysical Research: Earth Surface, 115(F3), doi:10.1029/2008JF001187.

Howard, A. D., and G. Kerby (1983), Channel changes in badlands, Geological Society of America Bulletin, 94(6), 739-752, doi:10.1130/0016-7606(1983)943C739:CCIB3E2. $0 . \mathrm{CO} ; 2$.

Howard, A. D., and R. Kochel (1988), Introduction to cuesta landforms and sapping processes on the Colorado Plateau, in Sapping Features of the Colorado Plateau: A Comparative Planetary Geology Field Guide, vol. 491, p. 6, Scientific and Technical Information Office, National Aeronautics and Space Administration, Springfield, Va.

Lague, D. (2014), The stream power river incision model: evidence, theory and beyond, Earth Surface Processes and Landforms, 39(1), 38-61, doi:10.1002/esp.3462.

Lamb, M. P., A. D. Howard, J. Johnson, K. X. Whipple, W. E. Dietrich, and J. T. Perron (2006), Can springs cut canyons into rock?, Journal of Geophysical Research: Planets, 111 (E7), doi:10.1029/2005JE002663.

Lamb, M. P., A. D. Howard, W. E. Dietrich, and J. T. Perron (2007), Formation of amphitheater-headed valleys by waterfall erosion after large-scale slumping on Hawaii, Geological Society of America Bulletin, 119(7-8), 805-822, doi:10.1130/B25986.1.

Lamb, M. P., B. H. Mackey, and K. A. Farley (2014), Amphitheater-headed canyons formed by megaflooding at Malad Gorge, Idaho, Proceedings of the National Academy of Sciences, $111(1), 57-62$, doi:10.1073/pnas.1312251111. 
694

695

696

Mackey, B. H., J. S. Scheingross, M. P. Lamb, and K. A. Farley (2014), Knickpoint formation, rapid propagation, and landscape response following coastal cliff retreat at the last interglacial sea-level highstand: Kaua'i, Hawai'i, Geological Society of America Bulletin, 126(7-8), 925-942, doi:10.1130/B30930.1.

Mason, P. J., and K. Arumugam (1985), Free jet scour below dams and flip buckets, Journal of Hydraulic Engineering, 111(2), 220-235.

Melis, T. S., W. M. Phillips, R. H. Webb, and D. J. Bills (1996), When the blue-green waters turn red: Historical flooding in Havasu Creek, Arizona, US Geological Survey water-resources investigations report, pp. 96-4059.

Montgomery, D. C., and G. C. Runger (2010), Applied statistics and probability for engineers, John Wiley \& Sons, New York.

Montgomery, D. R., and J. M. Buffington (1997), Channel-reach morphology in mountain drainage basins, Geological Society of America Bulletin, 109(5), 596-611, doi:10.1130/ 0016-7606(1997)109<0596:CRMIMD>2.3.CO;2.

Montgomery, D. R., J. M. Buffington, R. D. Smith, K. M. Schmidt, and G. Pess (1995), Pool spacing in forest channels, Water Resources Research, 31(4), 1097-1105, doi:10. 1029/94WR03285.

Moon, S., C. P. Chamberlain, K. Blisniuk, N. Levine, D. H. Rood, and G. E. Hilley (2011), Climatic control of denudation in the deglaciated landscape of the Washington Cascades, Nature Geoscience, 4(7), 469-473, doi:10.1038/ngeo1159.

Mudd, S. M., M. Attal, D. T. Milodowski, S. W. Grieve, and D. A. Valters (2014), A statistical framework to quantify spatial variation in channel gradients using the integral method of channel profile analysis, Journal of Geophysical Research: Earth 
Surface, 119(2), 138-152, doi:10.1002/2013JF002981.

Murphy, B. P., J. P. Johnson, N. M. Gasparini, and L. S. Sklar (2016), Chemical weathering as a mechanism for the climatic control of bedrock river incision, Nature, 532(7598), 223-227, doi:10.1038/nature17449.

Niemann, J. D., N. M. Gasparini, G. E. Tucker, and R. L. Bras (2001), A quantitative evaluation of Playfair's law and its use in testing long-term stream erosion models, Earth Surface Processes and Landforms, 26(12), 1317-1332, doi:10.1002/esp.272.

Perron, J. T., and L. Royden (2012), An integral approach to bedrock river profile analysis, Earth Surface Processes and Landforms, 38, doi:10.1002/esp.3302.

Rodríguez, E., C. Morris, J. Belz, E. Chapin, J. Martin, W. Daffer, and S. Hensley (2005), An assessment of the SRTM topographic products, Tech. rep., JPL D-31639, Jet Propulsion Laboratory, Pasadena, California.

Rosenbloom, N. A., and R. S. Anderson (1994), Hillslope and channel evolution in a marine terraced landscape, Santa Cruz, California, Journal of Geophysical Research: Solid Earth, 99 (B7), 14,013-14,029, doi:10.1029/94JB00048.

Royden, L., and T. J. Perron (2013), Solutions of the stream power equation and application to the evolution of river longitudinal profiles, Journal of Geophysical Research: Earth Surface, 118(2), 497-518, doi:10.1002/jgrf.20031.

Royden, L., M. Clark, and K. Whipple (2000), Evolution of river elevation profiles by bedrock incision: Analytical solutions for transient river profiles related to changing uplift and precipitation rates, Eos Trans. AGU, 81, 48.

Ruiz, G. M. H. (2002), Exhumation of the northern Sub-Andean Zone of Ecuador and its source regions, Ph.D. thesis, Diss., Naturwissenschaften ETH Zürich, Nr. 14905, 2003. 
Scheingross, J. S., and M. P. Lamb (2016), Sediment transport through self-adjusting, bedrock-walled waterfall plunge pools, Journal of Geophysical Research: Earth Surface, doi:10.1002/2015JF003620.

Scheingross, J. S., D. Y. Lo, and M. P. Lamb (2017), Self-formed waterfall plunge pools in homogeneous rock, Geophysical Research Letters, 44(1), 200-208, doi:10.1002/ 2016GL071730.

Seidl, M., and W. Dietrich (1992), The problem of channel erosion into bedrock, in Functional Geomorphology: Landform Analysis and Models: festschrift for Frank Ahnert, vol. Catena Supplement 23, edited by K. Schmidt and J. de Ploey, pp. 101-124, Cremlingen, Germany, Catena Verlag.

Shelef, E., and G. E. Hilley (2014), Symmetry, randomness, and process in the structure of branched channel networks, Geophysical Research Letters, 41(10), 3485-3493, doi: 10.1002/2014GL059816.

Stock, J. D., and D. R. Montgomery (1999), Geologic constraints on bedrock river incision using the stream power law, Journal of Geophysical Research. B, 104, 4983-4993, doi: 10.1029/98JB0213.

Tucker, G., and G. Hancock (2010), Modeling landscape evolution, Earth Surface Processes and Landforms, 35(1), 28-50, doi:10.1002/esp.1952.

Tucker, G., and K. Whipple (2002), Topographic outcomes predicted by stream erosion models: Sensitivity analysis and intermodel comparison, Journal of Geophysical Research: Solid Earth, 107(B9), doi:10.1029/2001JB000162.

Weissel, J. K., and M. A. Seidl (1997), Influence of rock strength properties on escarpment retreat across passive continental margins, Geology, 25(7), 631-634, doi: 
10.1130/0091-7613(1997)025<0631:IORSPO > 2.3.CO;2.

Weissel, J. K., and M. A. Seidl (1998), Inland propagation of erosional escarpments and river profile evolution across the southeast Australian passive continental margin, Rivers over rock: fluvial processes in bedrock channels, pp. 189-206.

Whipple, K., and G. Tucker (1999), Dynamics of the stream-power river incision model: Implications for height limits of mountain ranges, landscape response timescales, and research needs, Journal of Geophysical Research, 104, 17,661-17,674, doi:10.1029/ 1999JB900120.

Whittaker, A. C., and S. J. Boulton (2012), Tectonic and climatic controls on knickpoint retreat rates and landscape response times, Journal of Geophysical Research: Earth Surface, $117(\mathrm{~F} 2)$, doi:10.1029/2011JF002157.

Willett, S. D., S. W. McCoy, J. T. Perron, L. Goren, and C.-Y. Chen (2014), Dynamic reorganization of river basins, Science, 343(6175), 1248,765, doi:10.1126/science.1248765.

Wobus, C., K. X. Whipple, E. Kirby, N. Snyder, J. Johnson, K. Spyropolou, B. Crosby, and D. Sheehan (2006a), Tectonics from topography: Procedures, promise, and pitfalls, Geological Society of America Special Papers, 398, 55-74, doi:10.1130/2006.2398(04).

Wobus, C. W., B. T. Crosby, and K. X. Whipple (2006b), Hanging valleys in fluvial systems: Controls on occurrence and implications for landscape evolution, Journal of Geophysical Research: Earth Surface, 111(F2), doi:10.1029/2005JF000406.

Zaprowski, B. J., F. J. Pazzaglia, and E. B. Evenson (2005), Climatic influences on profile concavity and river incision, Journal of Geophysical Research: Earth Surface, 110(F3), doi:10.1029/2004JF000138. 

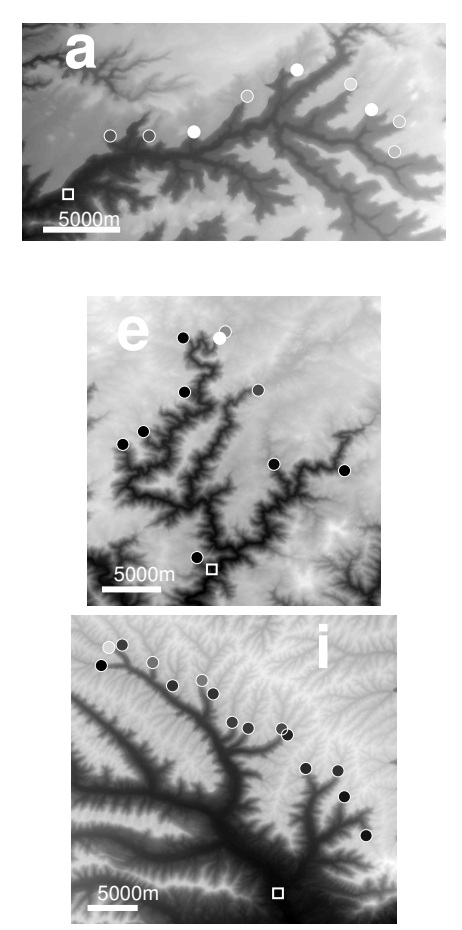
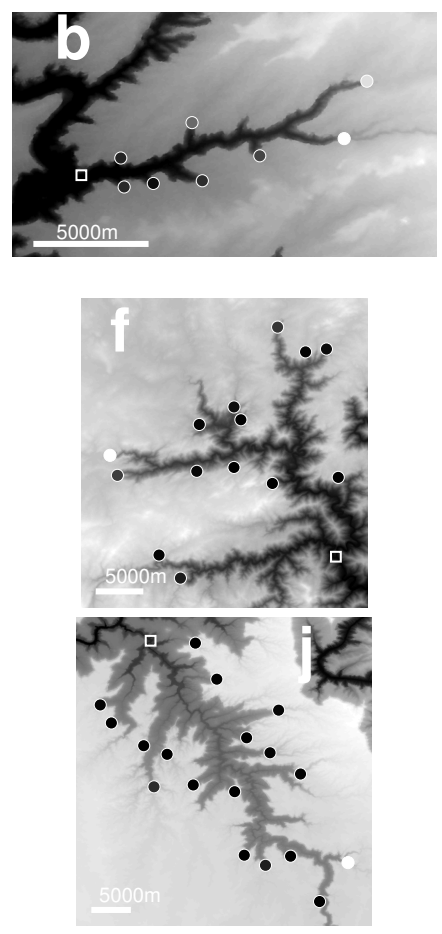
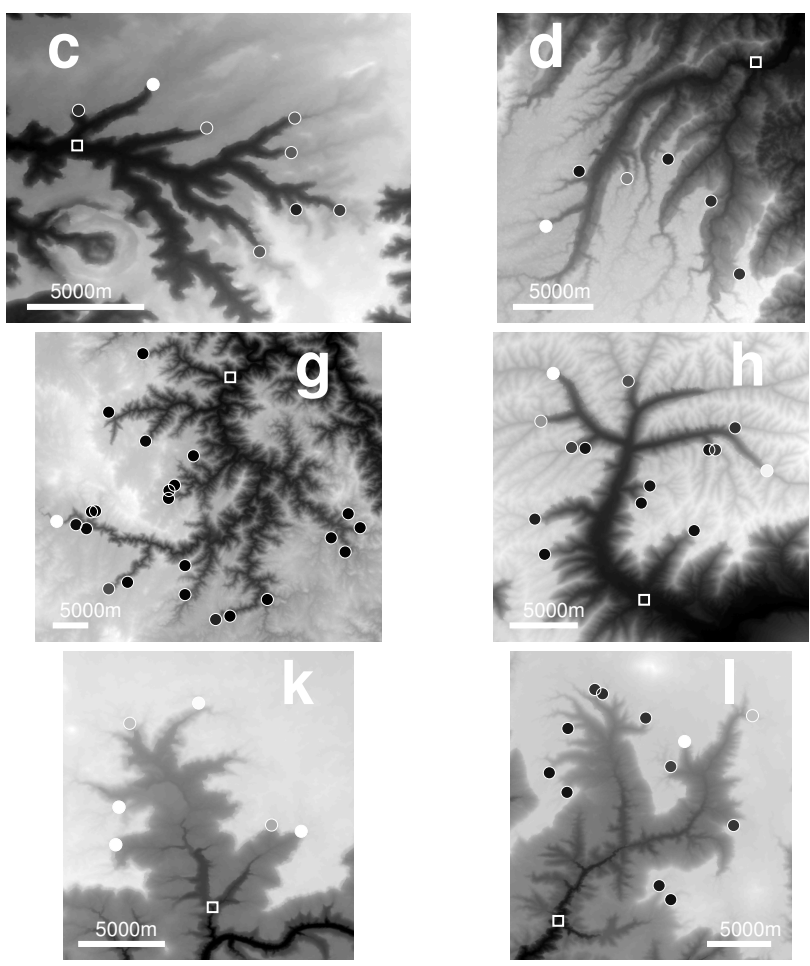

Figure 1: DEMs of the 12 basins analyzed in this study. Panels are labeled in accordance with the basin ID in Tables 1 and S1, where more information is provided regarding the location and characteristics of the different basins. Maps are shown in north to the top orientation and lighter colors represent higher elevation. Circles show the location of waterfalls and a white square shows the prescribed location of the initial waterfall for each basin. Circles are colored by relative drainage area at a waterfall within each basin $\left(A_{r}=\frac{A_{w}}{\operatorname{mean}\left(A_{w}\right)}\right.$, where light colors indicate high $A_{r}$, and $A_{w}$ is the drainage area at the waterfall) to illustrate the scatter in drainage area at waterfalls. Note that waterfalls in basins a and $\mathrm{k}$ have lower variation in $A_{r}$ values compared to other basins where some of waterfalls are associated with very high $A_{r}$ values (light color), while others with very low (dark color). Basin locations are: a-c: Utah, USA, d: Pastaza, Equador, e-g: New South Wales, Australia, h-i:Colorado, USA, j-l:Arizona, USA. 


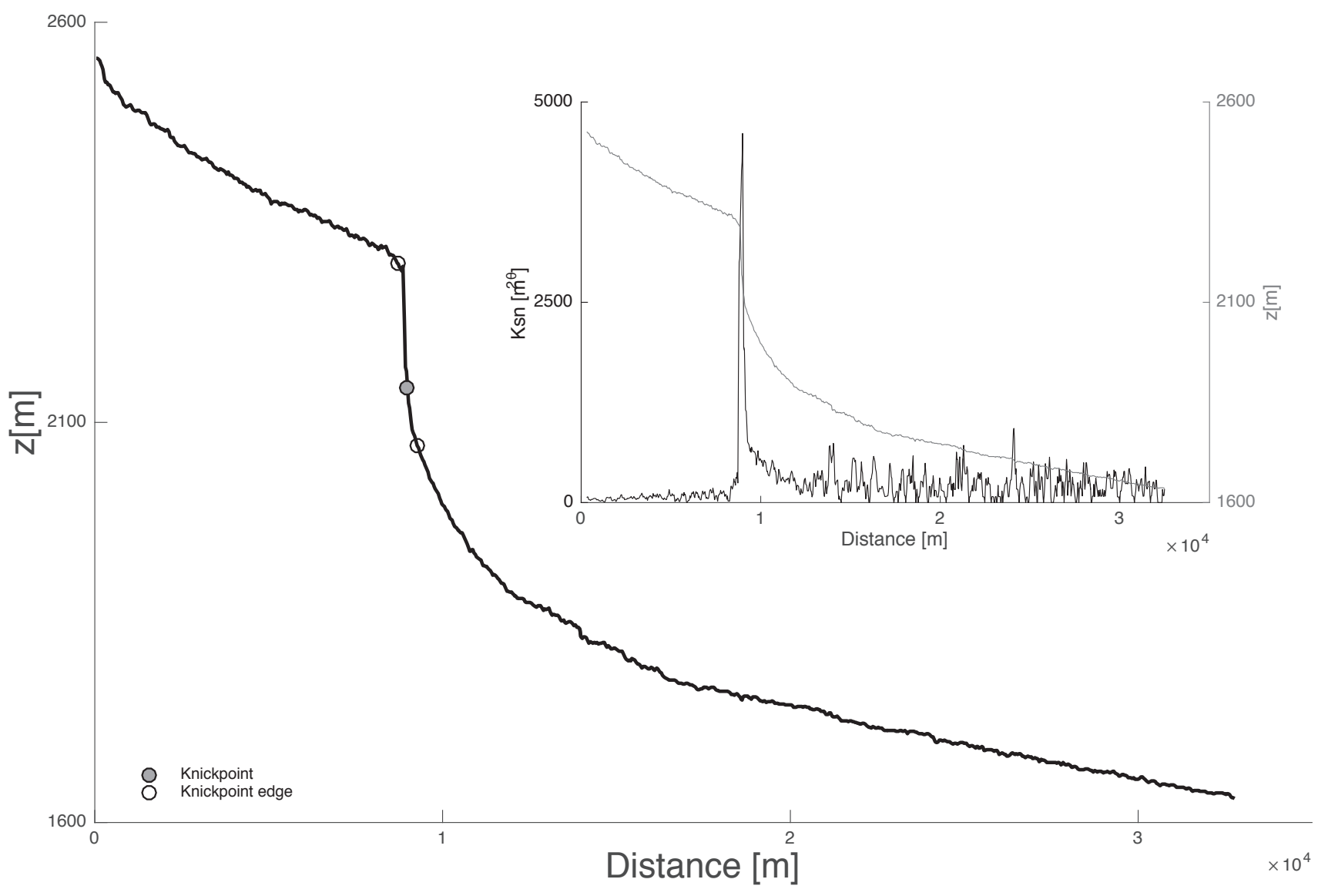

Figure 2: An example for quasi-automatic knickpoint detection. The main figure shows the profile of a channel in basin 1 (Figure 1) and the location of the detected knickpoint (filled circle) and its top and bottom boundaries (open circles). The inset graph shows the same profile (grey line, right y axis), and the associated $k_{s n}$ values (black line, left y axis). 

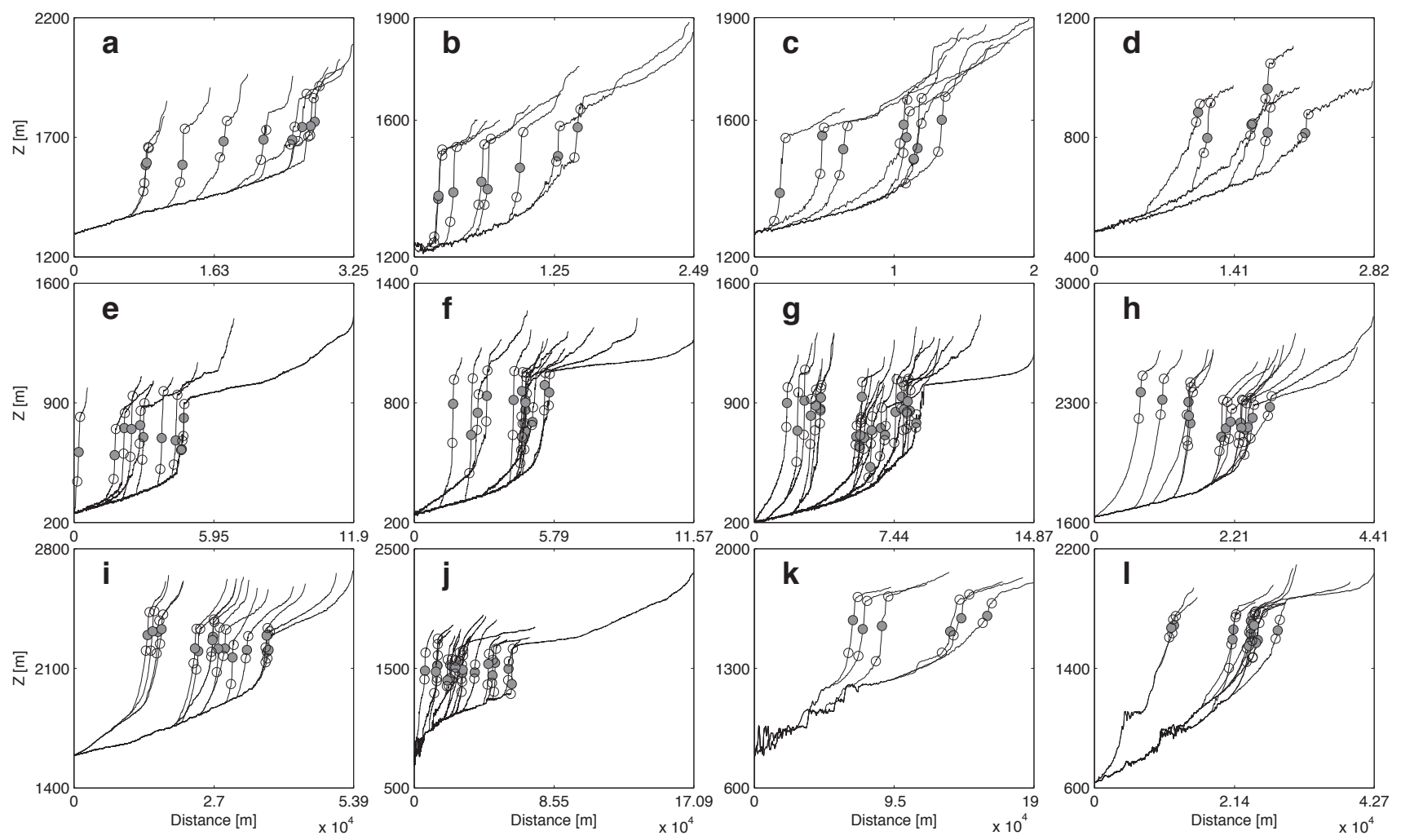

Figure 3: Topographic profiles along the analyzed channel systems. Each panel shows the profiles and the waterfalls for each basin and is labeled in accordance with the basin ID in Table 1. Dark and light colored circles mark the waterfalls and their boundaries, respectively. The lowest extent of the profiles is the prescribed location of the initial knickpoint. The jagged topography of some of the channels reflects the noisy DEM data (this plot shows the raw DEM data rather than a smoothed or pit-filled elevation data). 


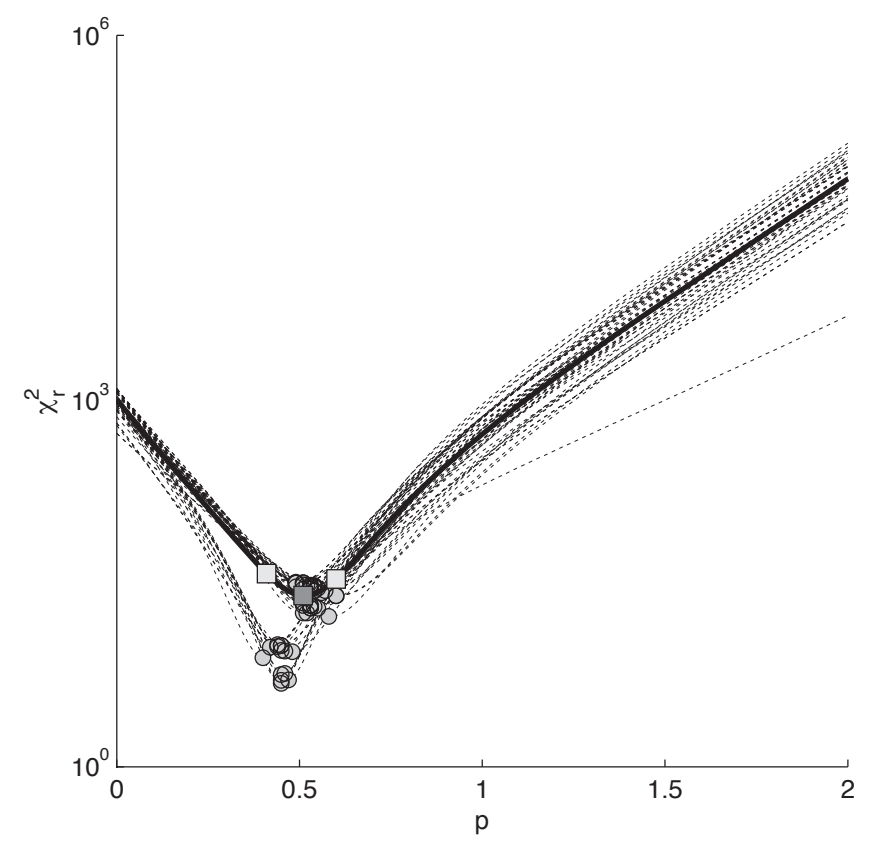

Figure 4: Optimization of $p$ and its associated uncertainty. $\chi_{r}^{2}$ (y axis) vs. different $p$ values (x axis) for one of the analyzed basins (basin h, Table 1). The solid line is an optimization curve based on all waterfalls, and the dark grey square marks the optimal $p$ value that minimizes $\chi_{r}^{2}$ for this case. Dashed lines show 50 optimization curves for arbitrarily chosen subsets of $75 \%$ of all waterfalls, and grey circles mark the optimal $p$ value for each of these iterations. Light squares mark the uncertainty in the optimal $p$ value for all waterfalls, where this uncertainty is determined from the 2.5 and 97.5 percentiles of the optimal $p$ values for the 50 subsets of waterfalls (i.e., the grey circles). 

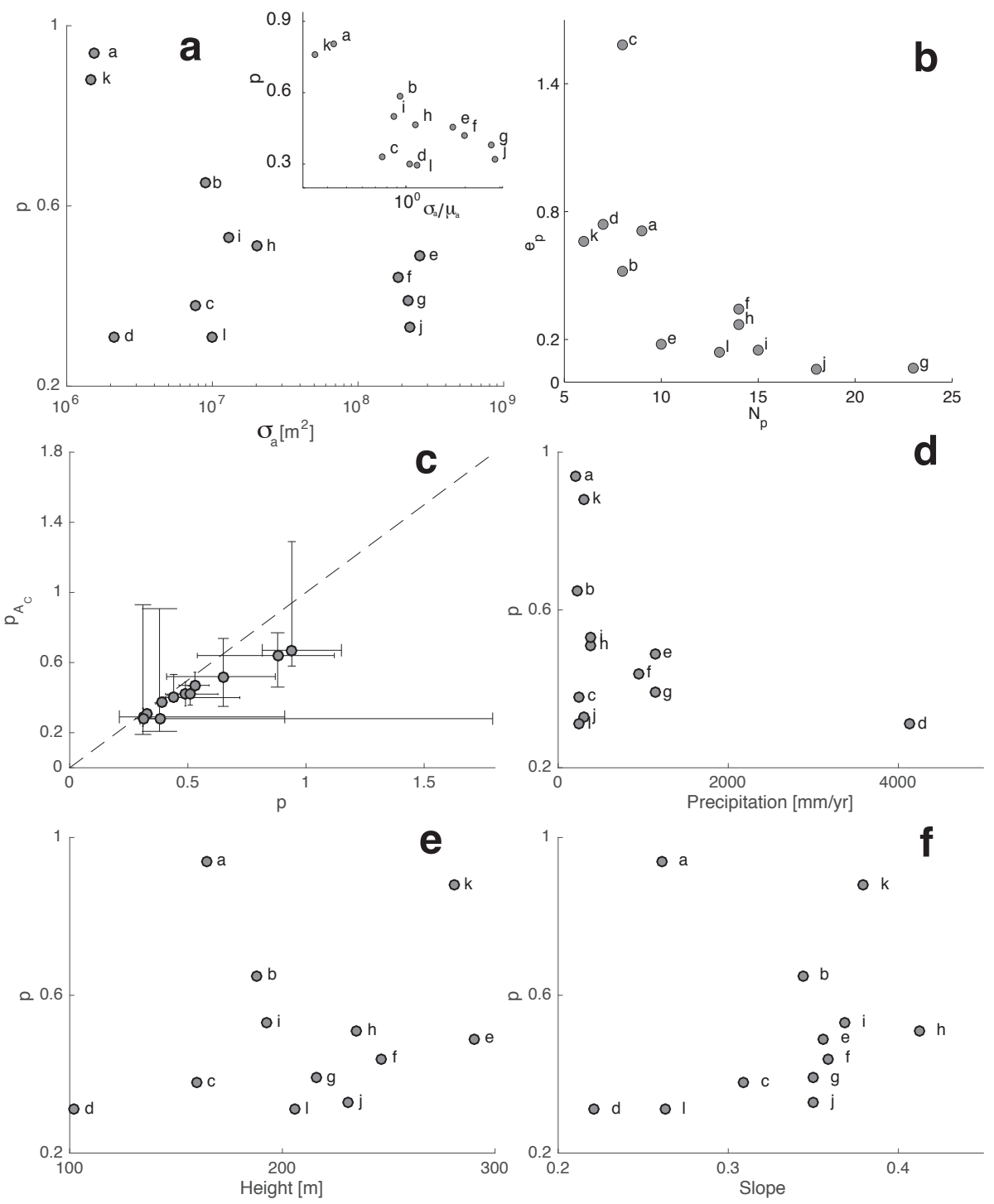

Figure 5: Basin parameters and their influence on $p$. (a) $p$ values (y axis) vs. the standard deviation of drainage area at the waterfalls $\left(\sigma_{a}\right)$. The inset shows the relative standard deviation $\sigma_{a} / \mu_{a}$, where $\mu$ is the mean drainage area at waterfalls $\left(A_{w}\right)$. (b) Uncertainty in $p\left(e_{p}\right.$; the difference between the highest and lowest uncertainty bounds of $p$ from models with and without a critical area threshold [y axis]) vs. the number of waterfalls within a basin ( $\mathrm{x}$ axis). (c) Comparison of $p$ value with $A_{c}>0$ (y-axis) and $A_{c}=0$ (x axis), where $A_{c}$ is a critical area threshold for waterfall recession. Dashed line shows a 1:1 relation. (d) $p$ value (y axis) vs. precipitation. (e) $p$ value (y axis) vs. mean waterfall height at a basin. (f) $p$ value (y axis) vs. mean value of slope between the waterfalls top and bottom boundaries at each basin. The $p$ value in plots d-f are the $p$ values computed with $A_{c}=0$. 

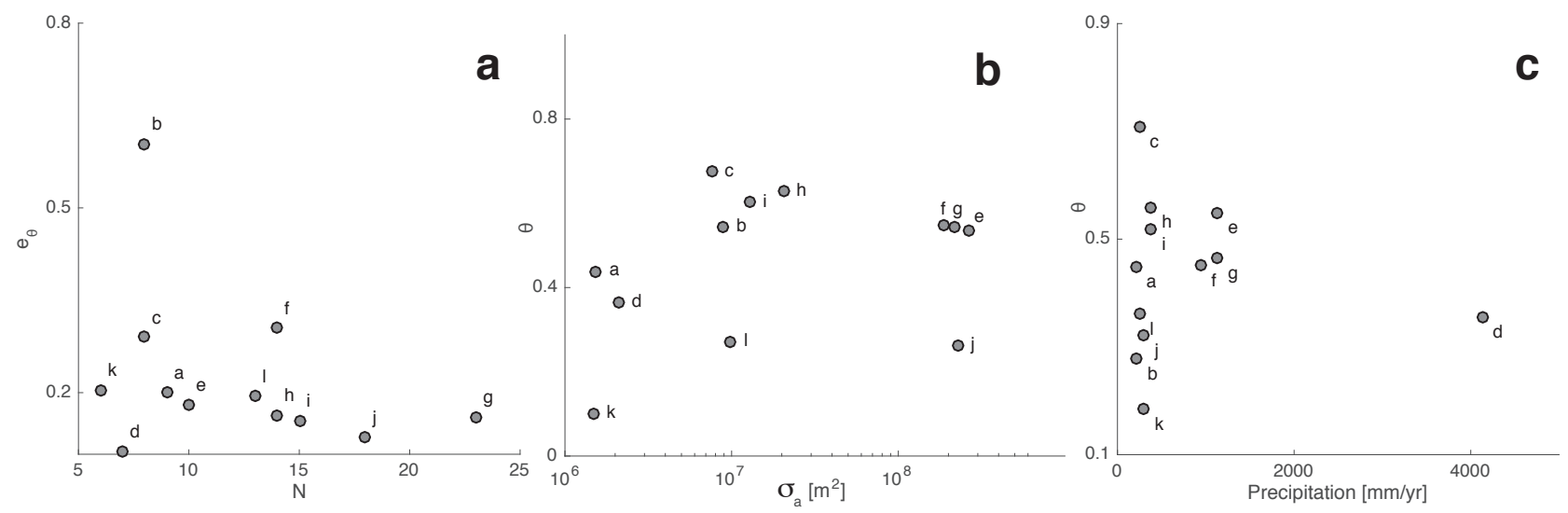

Figure 6: (a) The uncertainty in $\theta\left(e_{\theta}\right.$; the difference between the highest and lowest uncertainty bounds of the three methods used to compute $\theta$, y axis) vs. the number of waterfalls. (b) $\theta$ (y axis) vs. the standard deviation $\left(\sigma_{a}\right)$ of drainage area at waterfalls $\left(A_{w}\right)$. (c) $\theta$ (y axis) vs. precipitation. 

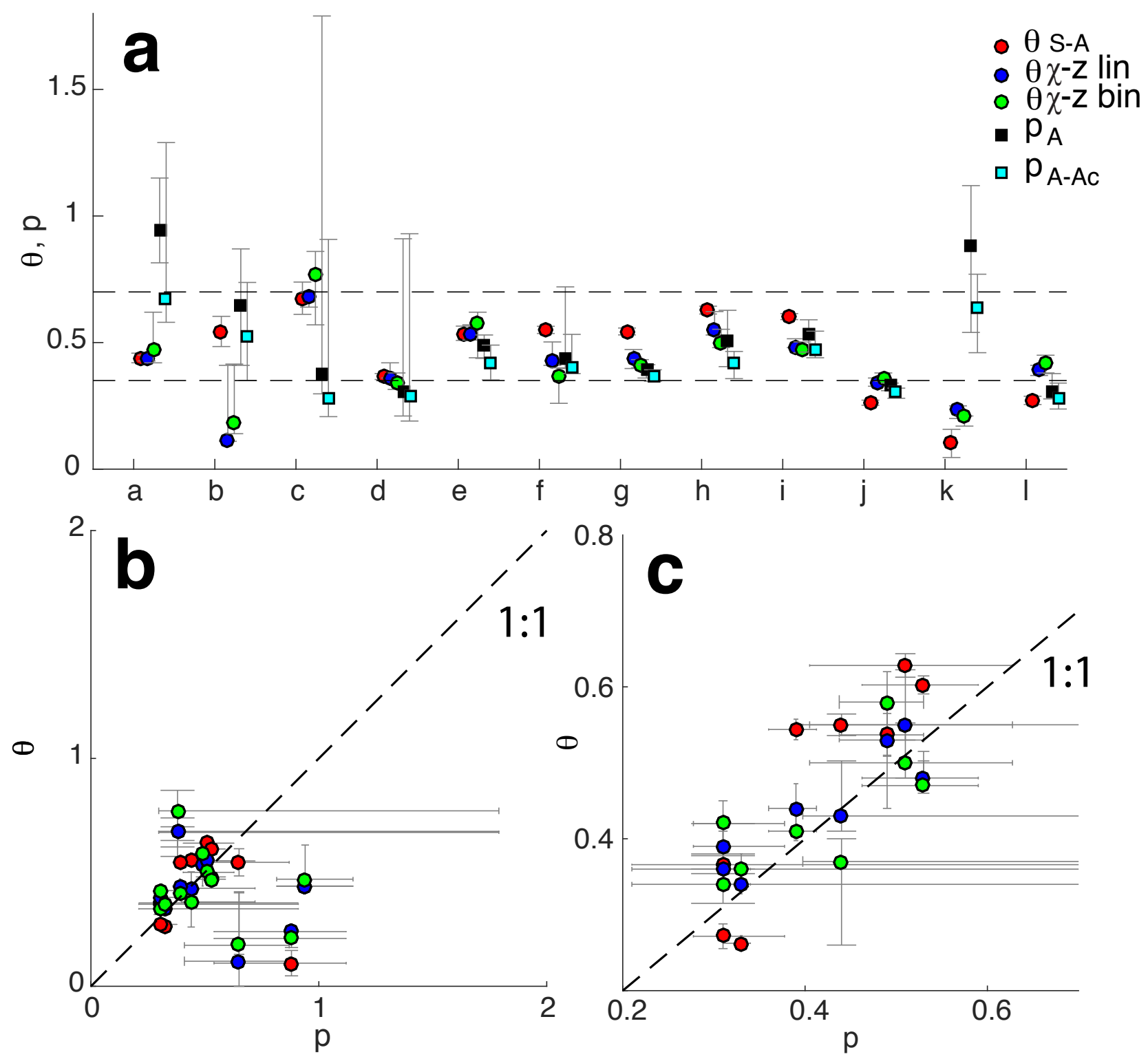

Figure 7: Computed $p$ and $\theta$ values. (a) comparison of $p$ and $\theta$ for different basins. The $\mathrm{x}$ axis shows the ID of the analyzed basins (in accordance with Table 1) and the y axis shows the value of $p$ and the values of $\theta$ for the various methods specified in the figure legend (Sections 2.4, 2.3). The uncertainty values are determined via the procedures described in Section 2.5. Note that the uncertainties of $p$ and $\theta$ overlap in most cases. The dashed horizontal lines mark the commonly observed $\theta$ values (0.35-0.7, [Whipple and Tucker, 1999; Tucker and Whipple, 2002]). (b) A scatter plot of $p$ (x-axis) vs $\theta$ (y axis) for all basins. The dashed line delineates a 1:1 relations between $p$ and $\theta$. $\theta$ values computed with different methods are colored as in panel a. Note that in many cases the uncertainties of $p$ and $\theta$ overlap with this 1:1 line. (c) Same as panel b, for basins with $\gtrsim 10$ waterfalls. This gives $R^{2}=0.64$ and a probability $(\mathrm{p})$ value of $2.4 \times 10^{-6}$. 

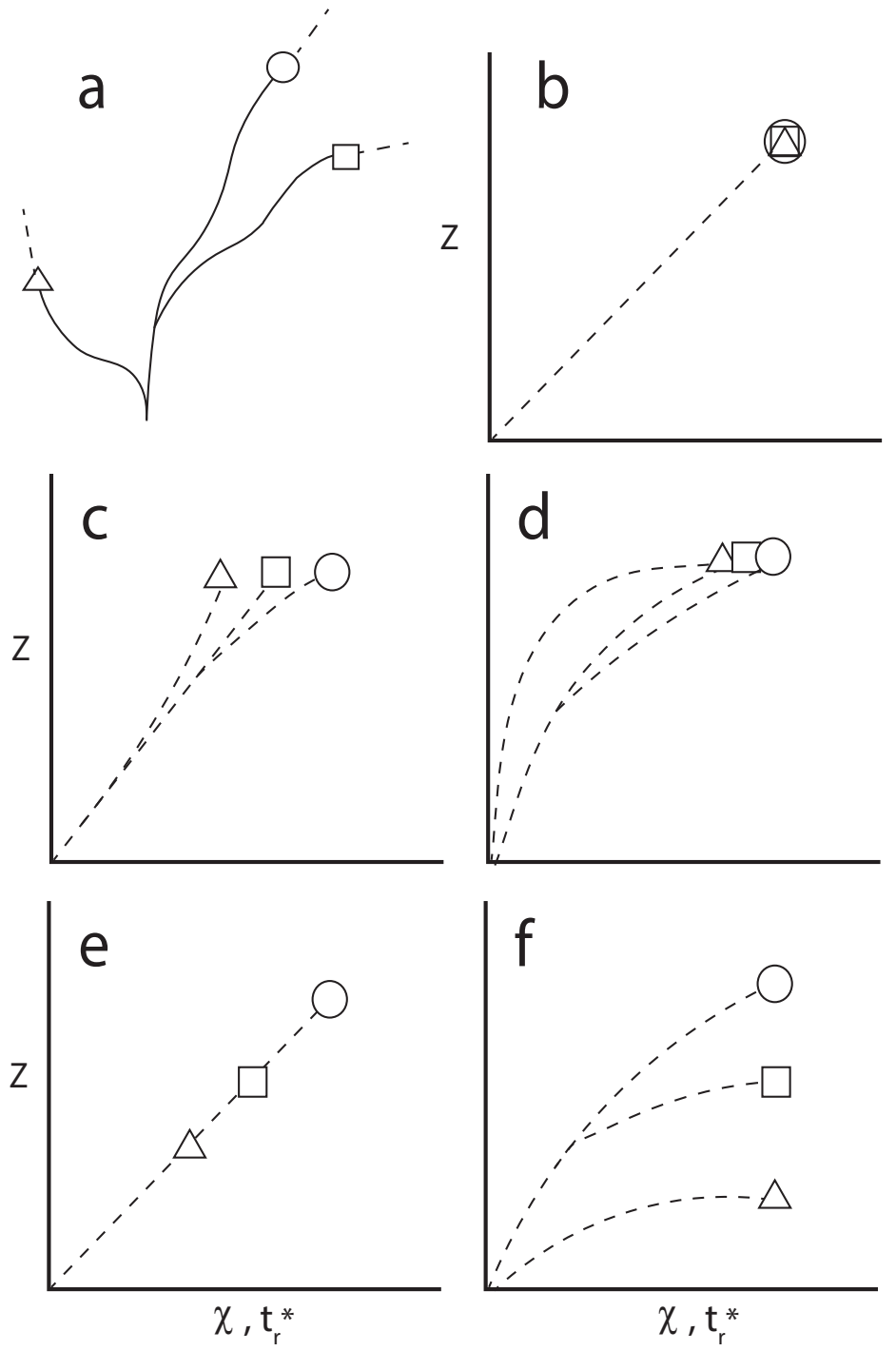

Figure 8: Schematic relations between $p$ and $\theta$ in $\chi-z$ space. (a) Schematic map of a basin with 3 waterfalls. waterfalls are marked with shapes, and the solid and dashed lines mark the channel downstream and upstream of the waterfall, respectively. (b) $\chi-z$ relations when all waterfalls lie at the same elevation. Here and in the following panels waterfalls are marked by shapes that correspond to those in panel a, and dashed line marks the $\chi-z$ values along the pathway from the origin to the waterfalls. (c) $\chi-z$ relations when waterfalls are at the same elevations and the $\theta$ value used to compute $\chi$ is that which minimizes the scatter in $z$ for a least square regression between $\chi$ and $z$. (d) $\chi-z$ relations when waterfalls are at the same elevations and the $p$ (or $\theta$ ) value used to compute the non-dimensional recession duration $t_{r}^{*}$ (or $\chi$ ) is that which minimizes the scatter in $t_{r}^{*}$ (or $\chi$ ) for the waterfall locations only. (e) $\chi-z$ relations when waterfalls are at different elevations and the $\theta$ value used to compute $\chi$ is that which minimizes the scatter in $z$ around a linear regression between $\chi$ and $z$. (f) $\chi-z$ relations when waterfalls are at different elevations and the $p$ (or $\theta$ ) value used to compute the non-dimensional recession duration $\left(t_{r}^{*}\right)$ is that which minimizes the scatter in $t_{r}^{*}$ (or $\chi$ ) for the waterfall locations only. 


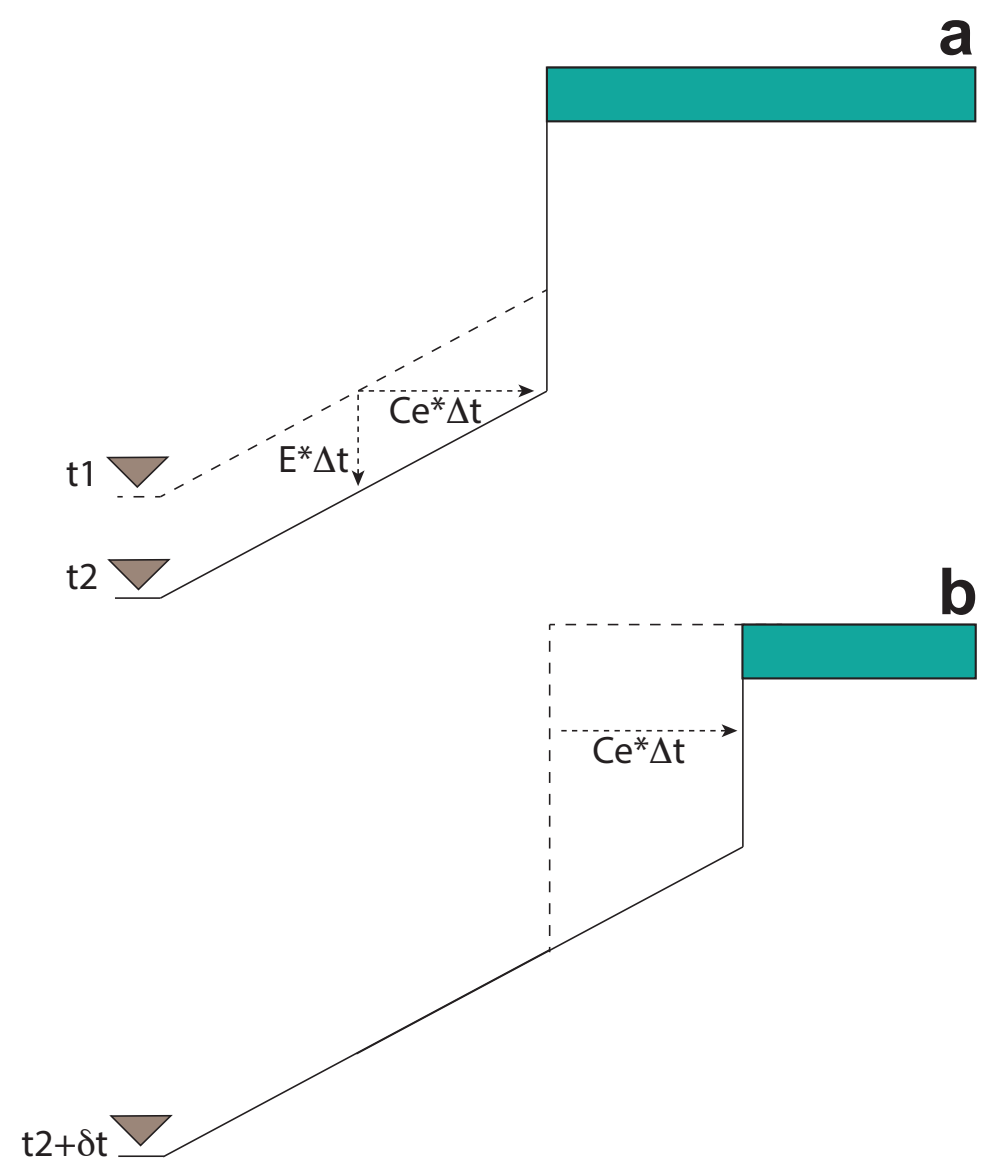

Figure 9: Schematic illustration of a recession mechanism that can cause similarity between the recession of non-vertical channels $\left(C_{e}\right)$ and waterfall recession $\left(C_{e w}\right)$ (i.e., $\left.C_{e} \simeq C_{e w}\right)$ over long time scales (after Haviv et al. [2010]). (a) Channel profile at times t1 (dashed line) and t2 (solid line). Grey triangles represents the base-level elevation in t1 and t2. $\Delta t$ is the time span between $\mathrm{t} 1$ and $\mathrm{t} 2$, such that $E * \Delta t$ is the depth of erosion $(E)$ downstream of the waterfall over this period and $C_{e} * \Delta t$ is the recession caused by this erosion. In this setting the cap-rock layer (colored in grey) is resistant to erosion whereas the underlying layers are of higher erodibility. (b) Channel profile following a gravitational collapse of the waterfall and downstream transport of the resulting debris (during a relatively short time period $\delta t$ ). The waterfall at time t2 (dashed line) can collapse through various processes (e.g., undercutting, toppling). Note that in that case the long term waterfall height is likely set by lithologic properties in conjunction with the gravitational collapse mechanism, and is constant in time and space as long as these properties are constant. Also note that the slope of the channel section downstream of the waterfall is $S=E / C_{e}$ (see dotted arrows in panel a), such that $C_{e}=E / S$ and $C_{e}=K A^{m} S^{n} / S=K A^{m} S^{n-1}$ in the context of the channel incision model. 

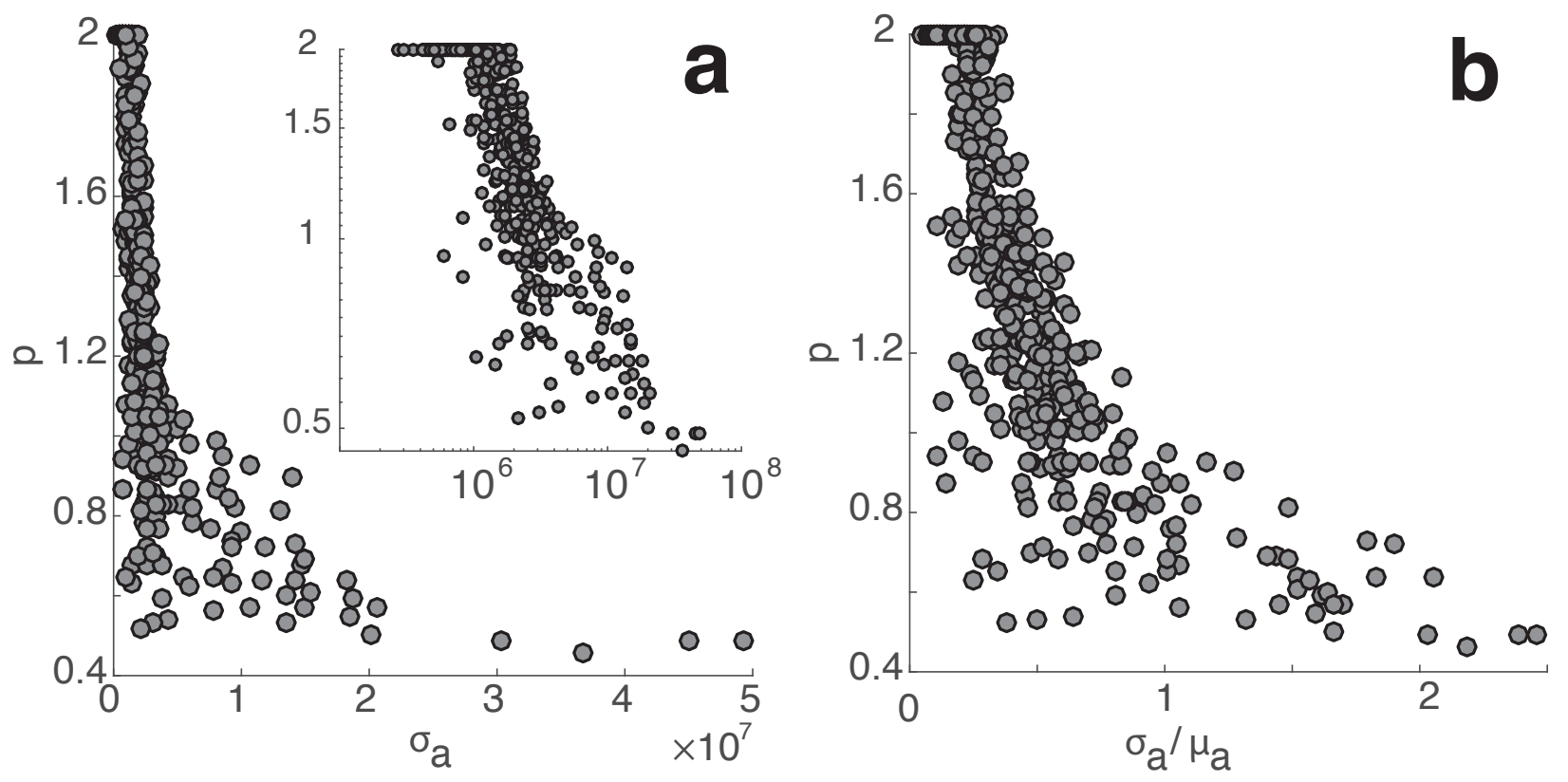

Figure 10: Relations between $p$ and $\sigma_{a}$ for experiments with arbitrary waterfall positioned in basin $g$ plotted in linear (a) and logarithmic (inset of panel a) scales. Each filled circle shows the values of $p$ and $\sigma_{a}$ for a single experiment with 11 waterfalls that are arbitrary positioned. (b) $p$ vs. the relative standard deviation in $A_{w}\left(\sigma_{a} / \mu_{a}\right)$. 
Table 1: Properties of the analyzed basins

\begin{tabular}{|c|c|c|c|c|c|c|c|}
\hline Basin ID & Basin name & Location & LAT & LON & $\begin{array}{l}\operatorname{MAP} \\
{[\mathrm{mm} / \mathrm{yr}]}\end{array}$ & Lithology & Studies of $p$ in this basin \\
\hline b & Mineral Canyon & Utah, USA & 38.531 & -109.976 & 200 & $\begin{array}{l}\text { Triasic sedimentary rocks [Chinle, Wingate, Kayenta } \\
\text { formations], primarily mudstone, sandstone, } \\
\text { limestone } 1 .\end{array}$ & - \\
\hline c & Taylor Canyon & Utah, USA & 38.475 & -109.941 & 250 & $\begin{array}{l}\text { Triasic sedimentary rocks [Chinle, Wingate, } \\
\text { Kayenta formations], primarily mudstone, } \\
\text { sandstone, limestone }{ }^{1} \text {. }\end{array}$ & - \\
\hline d & Rio Napo & $\begin{array}{l}\text { Pastaza, } \\
\text { Equador }\end{array}$ & -1.236 & -77.709 & 4150 & $\begin{array}{l}\text { Tertiary sedimentary rocks [Arajuno formations], } \\
\text { primarily conglomerate and sandstone }{ }^{2} \text {. }\end{array}$ & - \\
\hline e & Chandler River & $\begin{array}{c}\text { New South } \\
\text { Wales, Australia }\end{array}$ & -30.708 & 152.043 & 1150 & $\begin{array}{c}\text { Paleozoic metasedimentary rocks [Myra Beds and } \\
\text { undivided units], primarily schist, slate, phyllite, } \\
\text { greywacke, mudstone }\end{array}$ & $\begin{array}{l}\text { Weissel and Seidl [1998], } \\
\text { Weissel and Seidl [1997], } \\
\text { Seidel and Weisel [1996] }\end{array}$ \\
\hline $\mathbf{g}$ & Apsley River & $\begin{array}{c}\text { New South } \\
\text { Wales, Australia }\end{array}$ & -30.884 & 152.028 & 1150 & $\begin{array}{l}\text { Paleozoic metasedimentary rocks [Myra Beds and } \\
\text { undivided units], primarily schist, slate, phyllite, } \\
\text { greywacke, mudstone }\end{array}$ & $\begin{array}{l}\text { Weissel and Seidl [1998], } \\
\text { Weissel and Seidl [1997], } \\
\text { Seidel and Weisel [1996] }\end{array}$ \\
\hline h & Parachute Creek & Colorado, USA & 39.467 & -108.076 & 400 & $\begin{array}{c}\text { Tertiary sedimentary rocks [Wasatch and Green } \\
\text { River formations], primarily shale, sandstone, } \\
\text { marlstone }{ }^{4} \text {. }\end{array}$ & Berlin and Anderson [2007] \\
\hline $\mathbf{i}$ & Roan Creek & Colorado, USA & 39.406 & -108.269 & 400 & $\begin{array}{c}\text { Tertiary sedimentary rocks [Wasatch and Green } \\
\text { River formations], primarily shale, sandstone, } \\
\text { marlstone }{ }^{4} \text {. }\end{array}$ & Berlin and Anderson [2007] \\
\hline $\mathbf{j}$ & Havasu Creek & Arizona, USA & 36.272 & -112.719 & 300 & $\begin{array}{l}\text { Permian sedimentary rocks [Kaibab, Toroweap, } \\
\text { Coconino, Hermit fm], primarily limestone, shale, } \\
\text { sandstone }{ }^{5} \text {. }\end{array}$ & . \\
\hline
\end{tabular}

Basin ID are identical to those in Figure 1, latitude and longitude (decimal degrees) show the trunk channel location, MAP is the mean annual precipitation (rounded to the nearest $50 \mathrm{~mm} / \mathrm{yr}$ multiplier) computed from 0.5 degree dataset from precipitation data collected between 1901-1914 and attained from https://crudata.uea.ac.uk/cru/data/hrg/. The lithologic data is sourced from:

1 Source: http://files.geology.utah.gov/online/usgs/

2 Source: Ruiz [2002]

3 Source: http://www.resourcesandenergy.nsw.gov.au

4 Source: Berlin and Anderson [2007]; Hail Jr [1992]

${ }^{5}$ Source: http://pubs.usgs.gov/imap/ 